\title{
Institutional Quality and Stock Market Participation: Learning to Forget
}

\author{
Hossein Asgharian, Lu Liu and Frederik Lundtofte*
}

December 2013

\begin{abstract}
This paper explores how institutional quality affects stock market participation through its effect on individual trust. We develop a theoretical model in which higher institutional quality is likely to lead to a higher level of trust, and when the level of trust is sufficiently high, agents choose to invest in the stock market. We test our theory using European (SHARE) data on households residing in fourteen European countries. We find that institutional quality has a significant effect on trust and that trust (particularly the part that is explained by institutional quality) in turn significantly affects stock market participation. Moreover, since immigrants in many cases experience a dramatic change in institutional quality, we formulate and test hypotheses regarding immigrants' stock market participation relative to that of natives. We find that the impact of the institutional quality of immigrants' country of residence, relative to that of their country of origin, tends to increase with education.
\end{abstract}

Keywords: institutional quality, learning, trust, limited participation puzzle

JEL Codes: C13, G11

\footnotetext{
* Department of Economics and Knut Wicksell Centre for Financial Studies, Lund University. Frederik Lundtofte and Lu Liu gratefully acknowledge funding from the Crafoord and the Jan Wallander and Tom Hedelius Foundations. Corresponding author: Frederik Lundtofte, Department of Economics and Knut Wicksell Centre for Financial Studies, P.O. Box 7082, S-22007 Lund, Sweden. Email: frederik.lundtofte@nek.lu.se. Phone: +46 (0)46 22286 70. Fax: +46 (0)46 2224118 .
} 
"Man [..] cannot learn to forget, but hangs on the past: however far or fast he runs, that chain runs with him."

Friedrich Nietzsche, "The Use and Abuse of History"

\section{Introduction}

The ability to protect property rights is paramount to the development of financial markets and also to promoting economic growth in a market economy. If investors trust that financial contracts are being enforced and that the cost of fraudulent behavior is sufficiently high then, presumably, they are also more likely to invest. In an environment of low institutional quality where property rights are not being protected and there is no substantial punishment for fraudulent behavior, people become distrustful and less willing to engage in any type of financial contract that involves a counterparty to whom they have no personal ties. In such environments, social control becomes more important and may in some cases partially (at least locally) replace the punishing role of institutions. However, social control can never entirely replace the role of institutions, because social control applies only locally, whereas institutions have a much broader impact on attitudes and behavior. In well-functioning market economies with good institutions, people tend to trust each other and therefore they also enter financial contracts with counterparties with whom they have no previous ties. ${ }^{1}$

In this paper, we analyze the effects of institutional quality on stock market participation, both theoretically and empirically. We develop a theoretical model in which agents are Bayesian updaters who from time to time observe frauds, and this will form their level of trust. According to the model, higher institutional quality leads to a higher level of trust, and for a sufficiently high level of trust, agents want to invest in the stock market.

\footnotetext{
${ }^{1}$ See Bohnet and Steffen (2004) for evidence that better institutions lead to higher levels of trust.
} 
To the best of our knowledge, this is the first study on the effect of institutional quality on the degree of stock market participation, which accounts for the learning aspect in individuals' behavioral response to institutional quality.

We investigate the extent to which trust related to institutional quality affects individual investors' stock market participation. An interesting aspect resides in the fact that people may immigrate to other countries and experience a dramatic change in institutional quality. Over time, they should adopt a level of trust that is consistent with the institutional quality of their new country of residence and the degree of fraud in their country of origin should play a less important role in their decision making. However, many factors may affect the speed by which individuals adapt to the new country of residence. In our theoretical model we make the behavioral assumption that immigrants use a weighted average of fraud probabilities in their home country and in their new country of residence.

Based on our theory, we build an empirical model which investigates to what extent institutional quality affects trust and through that, stock market participation. In the case of immigrants, we analyze to what degree their level of trust is affected by the institutional quality of their home country relative to that of their new country of residence. Furthermore, we study if immigrants' degree of adaptation in this regard is related to their level of education.

We find strong support for our hypotheses: institutional quality significantly affects trust and the level of trust that is related to institutional quality has in turn a significant effect on the probability of stock market participation. Further, we find that immigrants' education is an important factor determining the relative impact of the institutional quality of the country of residence relative to that of the home country: the more time the immigrant households have spent on education, the larger is the impact of the institutional quality of the country of residence. Our interpretation is that highly educated immigrants learn the institutional quality 
of their new country of residence faster and assign a higher weight to it, whereas poorly educated immigrants are to a larger extent influenced by the institutional quality of their home countries. Our study is based on European survey data (the SHARE data set), covering more than 30,000 individuals in fourteen European countries. We first employ an ordered probit model to estimate expected trust related to institutional quality, in which the relative weight assigned by immigrants to the institutional quality of the country of residence and the country of origin is determined endogenously within the model, and is allowed to be a function of the immigrant's level of education. In the second step, we perform a standard probit analysis of the relationship between stock market participation and trust related to institutional quality.

We contribute to the literature on the "limited participation puzzle." 2 The theoretical explanations that have been put forward for this phenomenon include both rational ones, based on, e.g., transactions costs and liquidity needs (Allen and Gale, 1994; Williamson, 1994), ambiguity aversion (Dow and Werlang, 2002; Cao, Wang and Zhang, 2005; Epstein and Schneider, 2007), disappointment aversion (Ang, Bekaert and Liu, 2005) and behavioral ones, based on, e.g., loss aversion (Gomes, 2005), influence of social interaction (Hong, Kubik, and Stein, 2004; Brown, Ivković, Smith, and Weisbenner, 2008). More specifically, our paper is related to Osili and Paulson (2008a,b) and Guiso, Sapienza and Zingales (2008) who, among others, relate institutional environment and social capital to stock market participation $^{3}$. Osili and Paulson $(2008 \mathrm{a}, \mathrm{b})$ use data on immigrants to the US to investigate the impact of institutions on households' participation in financial markets. They find that the institutional quality of the country of origin has a large impact on a broad range of financial

\footnotetext{
${ }^{2}$ In short, the puzzle is that if the expected return on a stock exceeds the risk free rate, then, absent any frictions, everyone should participate in the stock market, albeit to varying degrees. However, we know that not all realworld investors participate in the stock market.

${ }^{3}$ The literature in this area also includes, e.g., Guiso, Sapienza, and Zingales (2004), Georgarakos and Pasini (2011), Christelis, Georgarakos, and Haliassos (2013).
} 
market behaviors, and that the effect of home country institutions is absorbed early in life. Guiso, Sapienza and Zingales (2008) investigate the effect of trust on stock market participation, and in their study of Dutch and Italian micro data, as well as cross-country data, lack of trust emerges as an important factor in explaining the stock market participation puzzle. In essence, we bring together and extend these papers. That is, compared to Osili and Paulson (2008a,b), we develop a model in which trust at the individual level is one of the key ingredients, and we make use of our data in this regard. Also, while Osili and Paulson (2008a,b) model the direct influence of institutions in the country of origin on immigrants' stock market participation in the U.S., we show that institutions affect stock market participation indirectly through their effect on trust. Moreover, because our data set spans respondents in fourteen different countries, we are able to add the institutional quality of the country of residence into the analysis and we study the interaction between and the relative importance of the country of origin's institutional quality, relative to that of the country of residence. Whereas Guiso, Sapienza and Zingales (2008) treat trust as exogenous, we analyze the formation of trust through learning in a repeated interaction model and investigate the impact of institutional quality on trust. We believe that our analysis allows for a better understanding of how the institutional quality of not only the country of origin, but also that of the country of residence affect stock market participation through trust.

The remainder of our paper is organized as follows. Section 2 presents our theory, which models how institutional quality forms trust through learning and how trust in turn affects stock market participation. Section 3 presents our empirical model. Section 4 describes the data and in Section 5, we present our empirical results. Finally, Section 6 concludes the paper. 


\section{Theory}

Drawing on Guiso, Sapienza and Zingales (2008), we develop a framework for analyzing how trust is formed and how it affects stock market participation. The main difference between our model and the one proposed by Guiso, Sapienza and Zingales (2008) is that we specifically consider the formation of trust through learning.

There are two assets available for investment: one stock and one short term bond. The short term gross interest rate is $R_{f}$, where $R_{f} \geq 1$. If there is fraud, then the stock's gross return is $\varepsilon$, where $\varepsilon>0$ is close to zero, and certainly less than one. In the absence of fraud, the stock delivers a gross return $\tilde{R}_{t}^{+}>\varepsilon .{ }^{4}$ We also assume that $E_{t}\left[\tilde{R}_{t+1}^{+}\right]>R_{f}$. Fraud occurs independently across periods. The probability of a fraud $(p)$ can either be high $\left(p=p_{h}\right)$ or low $\left(p=p_{l}\right)$, where $p_{h}>p_{l}$, but this probability does not change over time.

Agents maximize their expected utility of final wealth by choosing the relative allocation of their wealth to the stock $\left(\alpha_{t}\right)$. They have a short-selling constraint, meaning that $\alpha_{t} \geq 0$. For simplicity, we assume that agents have logarithmic utility. ${ }^{5}$ However, our main results regarding stock market participation also hold for myopic risk averse investors in general (given standard assumptions on the elementary utility function), as shown in Appendix A.1. Agents know the riskfree rate, the stock return if there is fraud and the distribution of the stock return if there is no fraud, but they do not know the probability of fraud. They update their probability of being in the state with a high probability of fraud using their historical observations on fraud in a Bayesian manner. Each agent has a prior regarding the probability

\footnotetext{
${ }^{4}$ In Guiso, Sapienza and Zingales (2008), $\varepsilon$ is equal to zero. Because we assume logarithmic utility, we need to let $\varepsilon$ be greater than zero.

${ }^{5}$ It is well-known that logarithmic utility induces myopic behavior (e.g., Mossin 1968, Hakansson 1971). This is important in this setting, because agents are learning about the probability of fraud, and thus, in general, the perceived investment opportunity set will change over time.
} 
of fraud: the prior is that the probability of fraud is high with probability $\theta_{0}$ (for ease of exposition, we suppress an index indicating what agent this prior belongs to). Let $D_{t}$ denote the number of frauds at time $t$. By Bayes theorem, agents' posterior probability of being in the state with a high probability of fraud is given by

$$
\begin{gathered}
\operatorname{Prob}\left(p=p_{h} \mid D_{t}=k\right)=\frac{\theta_{0} \operatorname{Prob}\left(D_{t}=k \mid p=p_{h}\right)}{\theta_{0} \operatorname{Prob}\left(D_{t}=k \mid p=p_{h}\right)+\left(1-\theta_{0}\right) \operatorname{Prob}\left(D_{t}=k \mid p=p_{l}\right)} \\
=\frac{\theta_{0}\left(\begin{array}{l}
t \\
k
\end{array}\right) p_{h}^{k}\left(1-p_{h}\right)^{t-k}}{\theta_{0}\left(\begin{array}{c}
t \\
k
\end{array}\right) p_{h}^{k}\left(1-p_{h}\right)^{t-k}+\left(1-\theta_{0}\right)\left(\begin{array}{l}
t \\
k
\end{array}\right) p_{l}^{k}\left(1-p_{l}\right)^{t-k}} \\
=\frac{\theta_{0} p_{h}^{k}\left(1-p_{h}\right)^{t-k}}{\theta_{0} p_{h}^{k}\left(1-p_{h}\right)^{t-k}+\left(1-\theta_{0}\right) p_{l}^{k}\left(1-p_{l}\right)^{t-k}} .
\end{gathered}
$$

At date $t=T-1$ (where $T$ is the final date), the agents' problem looks as follows (for ease of exposition, we suppress individual-specific indices):

$$
\begin{gathered}
\max _{\alpha_{T-1} \geq 0} \operatorname{Prob}\left(\widetilde{R}_{T}=\varepsilon \mid D_{T-1}\right) E_{T-1}\left[\ln \widetilde{W}_{T} \mid \tilde{R}_{T}=\varepsilon\right] \\
+\left(1-\operatorname{Prob}\left(\widetilde{R}_{T}=\varepsilon \mid D_{T-1}\right)\right) E_{T-1}\left[\ln \widetilde{W}_{T} \mid \tilde{R}_{T}>\varepsilon\right] \\
\text { s.t. } \widetilde{W}_{T}=W_{T-1}\left[R_{f}+\alpha_{T-1}\left(\tilde{R}_{T}-R_{f}\right)\right]
\end{gathered}
$$

Inserting the wealth constraint into the objective function, we find that solving the above maximization problem is equivalent to finding a non-negative $\alpha_{T-1}$ which maximizes the function

$$
\begin{gathered}
f_{T-1}\left(\alpha_{T-1}\right)=\operatorname{Prob}\left(\tilde{R}_{T}=\varepsilon \mid D_{T-1}\right) \ln \left(R_{f}+\alpha_{T-1}\left(\varepsilon-R_{f}\right)\right) \\
+\left(1-\operatorname{Prob}\left(\tilde{R}_{T}=\varepsilon \mid D_{T-1}\right)\right) E_{T-1}\left[\ln \left(R_{f}+\alpha_{T-1}\left(\tilde{R}_{T}^{+}-R_{f}\right)\right)\right] .
\end{gathered}
$$

We note that this function is strictly concave in $\alpha_{T-1}$. Therefore, the agent will participate in the stock market $\left(\alpha_{T-1}>0\right)$ if and only if $f_{T-1}{ }^{\prime}(0)>0$, or, equivalently, if and only if 


$$
\xi_{T-1} \equiv \frac{E_{T-1}\left[\tilde{R}_{T}^{+}-R_{f}\right]}{R_{f}-\varepsilon}>\frac{\operatorname{Prob}\left(\tilde{R}_{T}=\varepsilon \mid D_{T-1}\right)}{1-\operatorname{Prob}\left(\tilde{R}_{T}=\varepsilon \mid D_{T-1}\right)}
$$

We call $\xi_{t} \equiv E_{t}\left[\widetilde{R}_{t+1}^{+}-R_{f}\right] /\left(R_{f}-\varepsilon\right)$ the stock's normalized conditional risk premium at time $t$. By assumption, this is a strictly positive quantity. The interpretation of the condition in (4) is straightforward: in order for the agents to participate in the stock market, the total expected return on the stock needs to be greater than the risk free rate. Alternatively, we can say that the conditional expected return in the absence of fraud needs to be sufficiently large, or, the probability of fraud needs to be sufficiently small.

The problem clearly has a recursive structure. As we solve the maximization problem working backwards period-by-period until we reach time 0 , the problem looks as follows at date $t=T-q$.

$$
\begin{gathered}
\max _{\alpha_{T-q} \geq 0} \operatorname{Prob}\left(\tilde{R}_{T-q+1}=\varepsilon \mid D_{T-q}\right) E_{T-q}\left[\ln \widetilde{W}_{T} \mid \tilde{R}_{T-q+1}=\varepsilon\right] \\
+\left(1-\operatorname{Prob}\left(\tilde{R}_{T-q+1}=\varepsilon \mid D_{T-q}\right)\right) E_{T-q}\left[\ln \widetilde{W}_{T} \mid \tilde{R}_{T-q+1}>\varepsilon\right] \\
\text { s.t. } \widetilde{W}_{T}=W_{T-q-1}\left[R_{f}+\alpha_{T-q}\left(\tilde{R}_{T-q+1}-R_{f}\right)\right] \prod_{i=1}^{i=q-1}\left[R_{f}+\alpha_{T-i}^{*}\left(\tilde{R}_{T-i+1}-R_{f}\right)\right]
\end{gathered}
$$

where the $\alpha_{T-i}^{*}$ :s are the optimal solutions from the previously solved problems.

Due to the additivity of the logarithmic function, solving the above maximization problem is equivalent to finding a non-negative $\alpha_{T-q}$ which maximizes the function

$$
\begin{gathered}
f_{T-q}\left(\alpha_{T-q}\right)=\operatorname{Prob}\left(\tilde{R}_{T-q+1}=\varepsilon \mid D_{T-q}\right) \ln \left(R_{f}+\alpha_{T-q}\left(\varepsilon-R_{f}\right)\right) \\
+\left(1-\operatorname{Prob}\left(\tilde{R}_{T-q+1}=\varepsilon \mid D_{T-q}\right)\right) E_{T-q}\left[\ln \left(R_{f}+\alpha_{T-1}\left(\tilde{R}_{T-q+1}^{+}-R_{f}\right)\right)\right]
\end{gathered}
$$

Repeating the arguments above, the agent will participate in the stock market if and only if

$$
\xi_{T-q} \equiv \frac{E_{T-q}\left[\tilde{R}_{T-q+1}^{+}-R_{f}\right]}{R_{f}-\varepsilon}>\frac{\operatorname{Prob}\left(\tilde{R}_{T-q+1}=\varepsilon \mid D_{T-q}\right)}{1-\operatorname{Prob}\left(\tilde{R}_{T-q+1}=\varepsilon \mid D_{T-q}\right)}, q=1,2, \ldots, T,
$$


meaning that, for time $t=1,2, \ldots, T-1$, the condition for stock market participation is given by

$$
\xi_{t} \equiv \frac{E_{t}\left[\tilde{R}_{t+1}^{+}-R_{f}\right]}{R_{f}-\varepsilon}>\frac{\operatorname{Prob}\left(\tilde{R}_{t+1}=\varepsilon \mid D_{t}\right)}{1-\operatorname{Prob}\left(\tilde{R}_{t+1}=\varepsilon \mid D_{t}\right)},
$$

or, written differently,

$$
\operatorname{Prob}\left(\tilde{R}_{t+1}=\varepsilon \mid D_{t}\right)<\frac{\xi_{t}}{1+\xi_{t}}
$$

The condition for stock market participation in (8) will also hold for any myopic investor with a strictly increasing, strictly concave and twice-continuously differentiable elementary utility function $u$ satisfying $\lim _{W \rightarrow 0} u^{\prime}(W)=+\infty$ (see Appendix A.1).

We can use the law of total probability to calculate the probability of fraud: ${ }^{6}$

$$
\begin{gathered}
\operatorname{Prob}\left(\tilde{R}_{t+1}=\varepsilon \mid D_{t}=k\right)= \\
\operatorname{Prob}\left(p=p_{h} \mid D_{t}=k\right) \cdot \operatorname{Prob}\left(\tilde{R}_{t+1}=\varepsilon \mid D_{t}=k, p=p_{h}\right)+ \\
+\operatorname{Prob}\left(p=p_{l} \mid D_{t}=k\right) \cdot \operatorname{Prob}\left(\tilde{R}_{t+1}=\varepsilon \mid D_{t}=k, p=p_{l}\right) \\
=\frac{\theta_{0} p_{h}^{k+1}\left(1-p_{h}\right)^{t-k}+\left(1-\theta_{0}\right) p_{l}^{k+1}\left(1-p_{l}\right)^{t-k}}{\theta_{0} p_{h}^{k}\left(1-p_{h}\right)^{t-k}+\left(1-\theta_{0}\right) p_{l}^{k}\left(1-p_{l}\right)^{t-k}}
\end{gathered}
$$

We note that this probability is between $p_{l}$ and $p_{h}$. By the above equation, the condition for stock market participation in (8) can be rewritten as

$$
\xi_{t}>\frac{\theta_{0} p_{h}^{k+1}\left(1-p_{h}\right)^{t-k}+\left(1-\theta_{0}\right) p_{l}^{k+1}\left(1-p_{l}\right)^{t-k}}{\theta_{0} p_{h}^{k}\left(1-p_{h}\right)^{t-k+1}+\left(1-\theta_{0}\right) p_{l}^{k}\left(1-p_{l}\right)^{t-k+1}}
$$

The boundary for the normalized risk premium is increasing in the prior $\theta_{0}$, because, as can be seen from dividing through by $\theta_{0}$ both in the numerator and the denominator of the righthand side of (11), and taking the derivative with respect to $1 / \theta_{0}$, we have that this is given by

\footnotetext{
${ }^{6}$ Notice that $\operatorname{Prob}\left(\tilde{R}_{t+1}=\varepsilon \mid D_{t}=k, p=p_{h}\right)=p_{h}$ and $\operatorname{Prob}\left(\tilde{R}_{t+1}=\varepsilon \mid D_{t}=k, p=p_{l}\right)=p_{l}$.
} 


$$
\frac{p_{l}^{k}\left(1-p_{l}\right)^{t-k} p_{h}^{k}\left(1-p_{h}\right)^{t-k}\left(p_{l}-p_{h}\right)}{\left(p_{h}^{k}\left(1-p_{h}\right)^{t-k+1}-p_{l}^{k}\left(1-p_{l}\right)^{t-k+1}+\frac{1}{\theta_{0}} p_{l}^{k}\left(1-p_{l}\right)^{t-k+1}\right)^{2}}<0 .
$$

Thus, if the prior probability of the state with high probability of fraud increases, the expected return on the stock in the absence of fraud needs to be higher in order for the agent to participate in the stock market. As summarized in the following lemma, we can also show that, if the normalized risk premium $\left(\xi_{t}\right)$ lies between $p_{l} /\left(1-p_{l}\right)$ and $p_{h} /\left(1-p_{h}\right)$, then the prior probability required to induce stock market participation is lower the larger the number of observed frauds $(k)$. The interpretation of the bounds on the normalized risk premium is that in order for it to be possible to satisfy (11) with a lower prior, $\xi_{t}$ has to be greater than $p_{l} /\left(1-p_{l}\right)$, which is the lowest possible value on the right-hand side limit in (11). Moreover, if $\xi_{t}>p_{h} /\left(1-p_{h}\right)$, then all priors $\theta_{0} \in[0,1]$ will induce participation, because $p_{h} /\left(1-p_{h}\right)$ is the highest possible value on the right-hand side limit in (11). ${ }^{7}$

Lemma 1: Suppose $\frac{p_{l}}{1-p_{l}}<\xi_{t}<\frac{p_{h}}{1-p_{h}}$. Then, the prior probability $\left(\theta_{0}\right)$ required for stock market participation is decreasing in the number of observed frauds $(k)$.

Proof: By inverting the requirement for stock market participation in (11), we get

$$
\theta_{0}<\frac{p_{l}^{k}\left(1-p_{l}\right)^{t-k}\left[\left(1-p_{l}\right) \xi_{t}-p_{l}\right]}{p_{l}^{k}\left(1-p_{l}\right)^{t-k}\left[\left(1-p_{l}\right) \xi_{t}-p_{l}\right]+p_{h}^{k}\left(1-p_{h}\right)^{t-k}\left[p_{h}-\left(1-p_{h}\right) \xi_{t}\right]}
$$

Dividing both the numerator and the denominator by $p_{l}^{k}\left(1-p_{l}\right)^{t-k}$, we get to

$$
\theta_{0}<\frac{\left(1-p_{l}\right) \xi_{t}-p_{l}}{\left[\left(1-p_{l}\right) \xi_{t}-p_{l}\right]+\left(\frac{p_{h}\left(1-p_{l}\right)}{p_{l}\left(1-p_{h}\right)}\right)^{k}\left(\frac{1-p_{h}}{1-p_{l}}\right)^{t}\left[p_{h}-\left(1-p_{h}\right) \xi_{t}\right]}
$$

\footnotetext{
${ }^{7}$ If $\xi_{t}=p_{h} /\left(1-p_{h}\right)$, then all priors except $\theta_{0}=1$ will induce participation.
} 
We note that denominator in the right-hand side limit is increasing in $k$, meaning that the limit is decreasing in $k$, which in turn implies that the $\theta_{0}$ required for stock market participation is decreasing in the number of observed frauds $(k)$.

Now, consider two countries: country $H$ and country $L$. Country $H$ is a country with high institutional quality, and so in that country, the true probability of fraud is $p^{H}=p_{l}$ (but this is unknown to the investors) whereas country $L$ is a country with low institutional quality and the true probability of fraud is $p^{L}=p_{h}$. Each country has a continuum of investors with a positive mass and with identical distributions of priors in the interval $[0,1]$, with positive support for the entire interval. Investors can only invest in their country of residence, and the return distributions in the absence of fraud are identical, as are the interest rates.

Provided that $\xi_{t}>p_{l} /\left(1-p_{l}\right)$ and $\xi_{t}<p_{h} /\left(1-p_{h}\right)$, so that, if agents learn the true probability of fraud, no one in country $L$ will invest in the stock, whereas everyone in country $H$ will invest in the stock, we generally expect to see a higher degree of stock market participation in country $H$ than in country $L$. In fact, as $t$ increases, the probability that the citizens of country $L$ have experienced more frauds than the citizens of country $H$ increases as well. For large $t$, the number of frauds, which follows a binomial distribution, can be approximated by a normal distribution:

$$
\begin{aligned}
& \left(D_{t}^{H} \mid p^{H}=p_{l}\right) \sim N\left(t p_{l}, t p_{l}\left(1-p_{l}\right)\right) \\
& \left(D_{t}^{L} \mid p^{L}=p_{h}\right) \sim N\left(t p_{h}, t p_{h}\left(1-p_{h}\right)\right)
\end{aligned}
$$

Hence, provided that the number of frauds in country $H$ and the number of frauds in country $L$ are independent, then, for large $t$, the probability that the citizens of country $L$ have experienced more frauds than the citizens of country $H$ is given by

$$
\operatorname{Prob}\left(D_{t}^{L}>D_{t}^{H} \mid p^{L}=p_{h}, p^{H}=p_{l}\right)=\Phi\left(\frac{\left(p_{h}-p_{l}\right) \sqrt{t}}{\sqrt{p_{h}\left(1-p_{h}\right)+p_{l}\left(1-p_{l}\right)}}\right)
$$


where $\Phi($.$) is the cdf of a standard normal. Since p_{h}>p_{l}$, the above probability will approach one as $t$ gets larger. By Lemma 1, this means that the participation-inducing value of the prior probability of the state with a high probability of fraud is lower in country $L$ than in country $H$ with that same probability. In turn, this implies that, as $t$ gets larger, the probability that the fraction participating in the stock market is higher in country $H$ than in country $L$ also approaches one. Guided by the above reasoning, we formulate the following hypothesis.

Hypothesis 1: In countries with better institutional quality, people tend to have a higher level of trust, which in turn induces a higher degree of stock market participation in those countries.

Next, we compare the stock market participation between immigrants emigrating from country $L$ to country $H$ and natives in country $H$. Here, we make the behavioral assumption that immigrants use a weighted average of beliefs,

$$
\begin{gathered}
\operatorname{Prob}^{I}\left(\tilde{R}_{t+1}=\varepsilon \mid D_{t}^{L}, D_{t}^{H}\right) \\
=w(E) \operatorname{Prob}\left(\tilde{R}_{t+1}=\varepsilon \mid D_{t}^{H}\right)+(1-w(E)) \operatorname{Prob}\left(\tilde{R}_{t+1}=\varepsilon \mid D_{t}^{L}\right),
\end{gathered}
$$

where $E$ is the level of education. The higher the level of education $(E)$, the higher the weight assigned to the belief that is relevant for their new country of residence. The weighting of beliefs is thought to capture the phenomenon that immigrants' beliefs are affected by what happens and has happened in their home country, and more so if the level of education is lower: a well-educated immigrant forms his/her beliefs based on the history of events for the new country of residence to a larger extent. Of course, the weight $w(E)$ needs to be between zero and one. We let $w^{\prime}(E)>0$ for $0 \leq E<E_{\max }, w(0)=0, w\left(E_{\max }\right)=1$, where $E_{\max }$ is the maximum level of education. 
As $t$ increases in (16), the probability that $D_{t}^{L}>D_{t}^{H}$ approaches one. Therefore, we assume that $D_{t}^{L}>D_{t}^{H}$ in the following. It then follows that the probability that our conclusions will hold approaches one as $t$ increases.

If we compare immigrants with lower education than the maximum level $E_{\max }$ to natives and assume that the two groups have identical distributions of priors with positive support on $[0,1]$, we can conclude that a higher fraction of natives will invest in the stock market (provided that $p_{l} /\left(1-p_{l}\right)<\xi_{t}<p_{h} /\left(1-p_{h}\right)$ ).

Next, let us consider the effect of education on immigrants' stock market participation. Using a similar reasoning as in Lemma 1, we can establish that the highest participation-inducing prior belief is decreasing in the level of education (again provided that $p_{l} /\left(1-p_{l}\right)<\xi_{t}<$ $\left.p_{h} /\left(1-p_{h}\right)\right)$

Lemma 2: The rational probability of fraud given the number of observed frauds (see eq. (9)) is increasing in the number of observed frauds.

Proof: We can rewrite eq. (9) as

$$
\operatorname{Prob}\left(\tilde{R}_{t+1}=\varepsilon \mid D_{t}=k\right)=\frac{a p_{h}+b p_{l} f(k)}{a+b f(k)}
$$

where $a=\theta_{0}\left(1-p_{h}\right)^{t}, b=\left(1-\theta_{0}\right)\left(1-p_{l}\right)^{t}$, and

$$
f(k)=\left(\frac{p_{l}\left(1-p_{h}\right)}{\left(1-p_{l}\right) p_{h}}\right)^{k}
$$

Since $p_{h}>p_{l}$, we have that $f^{\prime}(k)<0$. Now, consider how the probability in (18) changes as we increase the number of observed frauds:

$$
\frac{\partial \operatorname{Prob}\left(\tilde{R}_{t+1}=\varepsilon \mid D_{t}=k\right)}{\partial k}=\frac{b a\left(p_{l}-p_{h}\right)}{(a+b f(k))^{2}} f^{\prime}(k)>0 .
$$


Lemma 3: Suppose $D_{t}^{L}>D_{t}^{H}$. Then, the prior probability $\left(\theta_{0}\right)$ required in order to reach a certain probability of fraud is increasing in the level of education $(E)$.

Proof: Here, we make use of the law of total differentiation, holding $\operatorname{Prob}^{I}\left(\tilde{R}_{t+1}=\right.$ $\left.\varepsilon \mid D_{t}^{L}, D_{t}^{H}\right)$ constant:

$0=\operatorname{dProb}{ }^{I}\left(\tilde{R}_{t+1}=\varepsilon \mid D_{t}^{L}, D_{t}^{H}\right)=w^{\prime}(E)\left(\operatorname{Prob}\left(\tilde{R}_{t+1}=\varepsilon \mid D_{t}^{H}\right)-\operatorname{Prob}\left(\tilde{R}_{t+1}=\right.\right.$

$\left.\left.\varepsilon \mid D_{t}^{L}\right)\right) d E+\left(w(E) \frac{\partial \operatorname{Prob}\left(\tilde{R}_{t+1}=\varepsilon \mid D_{t}^{H}\right)}{\partial \theta_{0}}+(1-w(E)) \frac{\partial \operatorname{Prob}\left(\tilde{R}_{t+1}=\varepsilon \mid D_{t}^{L}\right)}{\partial \theta_{0}}\right) d \theta_{0}$.

Hence, we have that

$\frac{d \theta_{0}}{d E}=-\frac{w^{\prime}(E)\left(\operatorname{Prob}\left(\tilde{R}_{t+1}=\varepsilon \mid D_{t}^{H}\right)-\operatorname{Prob}\left(\tilde{R}_{t+1}=\varepsilon \mid D_{t}^{L}\right)\right)}{w(E) \frac{\partial \operatorname{Prob}\left(\widetilde{R}_{t+1}=\varepsilon \mid D_{t}^{H}\right)}{\partial \theta_{0}}+(1-w(E)) \frac{\partial \operatorname{Prob}\left(\widetilde{R}_{t+1}=\varepsilon \mid D_{t}^{L}\right)}{\partial \theta_{0}}}>0, E \in\left[0, E_{\max }\right)$,

where the inequality is due to $w^{\prime}(E)>0, \frac{\partial \operatorname{Prob}\left(\tilde{R}_{t+1}=\varepsilon \mid D_{t}^{j}\right)}{\partial \theta_{0}}>0(j=H, L)$ and, by Lemma 2, $\operatorname{Prob}\left(\tilde{R}_{t+1}=\varepsilon \mid D_{t}^{H}\right)<\operatorname{Prob}\left(\tilde{R}_{t+1}=\varepsilon \mid D_{t}^{L}\right)$ because $D_{t}^{H}<D_{t}^{L}$.

The interpretation of Lemma 3 is that as education increases, a higher prior $\left(\theta_{0}\right)$ is needed to reach the lowest probability of fraud required for nonparticipation in the stock market. Now, consider a continuum of immigrants having a certain distribution of priors with positive support on $[0,1]$ and suppose that $\left.p_{l} /\left(1-p_{l}\right)<\xi_{t}<p_{h} /\left(1-p_{h}\right)\right)$. If we increase the level of education $E$, while holding everything else constant (including the distribution of priors), the prior needed to induce nonparticipation increases. That is, the higher the education of the immigrants, the higher the fraction of immigrants participating in the stock market. This leads us to formulate the following hypothesis.

Hypothesis 2: Immigrants who emigrate from a country of lower institutional quality tend to have lower trust, which in turn means that they tend to be less prone to participate in the 
stock market. This effect is more pronounced the lower the education of the immigrants, and the lower the institutional quality of their country of origin.

In Appendix A.2, we consider the effect of adding a fixed participation cost. This introduces interactions between wealth and trust. First, given that the investor would invest if there were no participation costs, there is a threshold level of wealth below which the investor would not participate. Second, this threshold level of wealth is increasing in the prior probability of fraud. Third, adding a participation cost lowers the prior probability of fraud that triggers nonparticipation.

\section{Empirical Model}

Based on our theoretical hypothesis, we construct an empirical model that investigates the degree to which stock market participation is affected by households' level of trust related to institutional quality. Our empirical model consists of two sequential parts. In the first part, we examine how institutional quality affects trust and in the second part we investigate the degree to which the level of trust that is explained by institutional quality affects stock market participation.

The first part of the empirical model defines the following relationship:

$$
T_{i}^{*}=\operatorname{func}\left(X_{i}\right)
$$

where, $T_{i}^{*}$ is the latent level of trust for individual $i$ and $X_{i}$ is the level of institutional quality experienced by individual $i$.

Since immigrants may have been exposed to completely different institutional conditions in their country of origin compared to the country of residence, we allow immigrants' level of trust to depend on a weighted average of institutional qualities in their country of residence and country of origin. Eq (24) is specified as 


$$
T_{i}^{*}=b_{N} D_{N, i} X_{i}^{r e s}+b_{I} D_{I, i}\left(w X_{i}^{r e s}+(1-w) X_{i}^{\text {ori }}\right)+\varepsilon_{i},
$$

where $X_{i}^{\text {res }}$ is the institutional quality of the country of residence for individual $i, X_{i}^{\text {ori }}$ is the institutional quality of the country of origin for immigrant $i, D_{N, i}$ is a dummy variable for natives, and $D_{I, i}$ is a dummy variable for immigrants. The parameter $w$ defines the weight of the institutional quality of the immigrants' country of residence. The equation can be written in the following form:

$$
T_{i}^{*}=b_{N} D_{N, i} X_{i}^{r e s}+b_{I} D_{I, i} X_{i}^{\text {ori }}+b_{I} w D_{I, i}\left(X_{i}^{r e s}-X_{i}^{\text {ori }}\right)+\varepsilon_{i}
$$

As hypothesized in Section 2, immigrants' degree of adaptation to the new institutional environment is related to their level of education. It seems plausible that immigrants with a higher level of education would learn the institutional quality of their new country of residence faster. To capture this learning process, we extend the model above and define the weight $w$ for each immigrant as a function of his or her level of education.

$$
\begin{gathered}
T_{i}^{*}=b_{N} D_{N, i} X_{i}^{r e s}+b_{I} D_{I, i} X_{i}^{\text {ori }}+b_{I} w_{i} D_{I, i}\left(X_{i}^{\text {res }}-X_{i}^{\text {org }}\right)+\varepsilon_{i}, \\
w_{i}=\frac{1}{1+\exp \left(-\gamma\left(E_{i}-c\right)\right)}
\end{gathered}
$$

where $E$ is the number of years spent on education, $c$ is the inflection point of the curve and $\gamma$ determines the shape of the curve (a small value corresponds to relatively smooth changes in function values). Such specification for $w$ assures that the value of $w$ is in the interval $[0,1]$.

$T_{i}^{*}$ is an unobservable continuous latent variable. What we can observe is a discrete ordinal variable, $T_{i}$, provided by the survey data SHARE. We assume the following censoring mechanism:

$$
T_{i}=j \text { if } \mu_{j-1}<T_{i}^{*} \leq \mu_{j}
$$

where $j=0,1,2 \ldots 10$, since in SHARE, the variable trust is an ordinal variable that goes from 
zero (low trust) to ten (high level of trust). We use ordered probit to estimate our models:

$$
\begin{gathered}
\operatorname{Prob}\left[T_{i}=j \mid \boldsymbol{X}_{i}^{T}\right]=\operatorname{Prob}\left[\varepsilon_{i} \leq \mu_{j}-\boldsymbol{\beta}^{\prime} \boldsymbol{X}_{i}^{T}\right]-\operatorname{Prob}\left[\varepsilon_{i} \leq \mu_{j-1}-\boldsymbol{\beta}^{\prime} \boldsymbol{X}_{i}^{T}\right] \\
=F\left(\mu_{j}-\boldsymbol{\beta}^{\prime} \boldsymbol{X}_{i}\right)-F\left(\mu_{j-1}-\boldsymbol{\beta}^{\prime} \boldsymbol{X}_{i}\right), \text { for } j=1,2, \ldots 10,
\end{gathered}
$$

Where $\mu_{-1}=-\infty, \mu_{10}=+\infty, \boldsymbol{X}_{i}^{T}=\left[1, D_{N, i} X_{i}^{\text {res }}, D_{I, i} X_{i}^{\text {org }}, D_{I, i}\left(X_{i}^{\text {res }}-X_{i}^{\text {org }}\right)\right]$ is a $4 \times 1$ vector of all the explanatory variables for individual $i$ in eq. (21) and $\boldsymbol{\beta}$ is the corresponding $4 \times 1$ parameter vector. We use the estimated parameters to calculate expected trust for individual $i$ conditional on the institutional quality experienced by individual $i$ :

$$
T_{i}^{i n s t}=E\left[T_{i} \mid \boldsymbol{X}_{i}^{T}\right]=\sum_{j=1}^{J} \operatorname{Prob}\left[T_{i}=j \mid \boldsymbol{X}_{i}^{T}\right] \times j .
$$

The second part of the analysis relates stock market participation to the expected level of trust that is explained by institutional quality. The dependent variable, stock market participation, is binary and coded as one if the household owns stocks and zero otherwise. The independent variables consist of the expected level of trust and a number of control variables:

$$
y_{i}^{*}=a_{0}+a_{1} T_{i}^{i n s t}+\sum_{k=1}^{K} a_{k+1} Z_{k i}+u_{i}
$$

where $y_{i}^{*}$ indicates the stock market participation of individual $i$ and $Z_{k i}$ is control variable $k$ for individual $i$. The conditional probability that individual $i$ participates in the stock market is then given by

$$
\operatorname{Prob}\left[y_{i}=1 \mid \boldsymbol{X}_{i}^{p}\right]=1-F\left(-\boldsymbol{\alpha}^{\prime} \boldsymbol{X}_{i}^{p}\right)
$$

where $\boldsymbol{X}_{i}^{P}$ is the vector of all the explanatory variables (including one) for individual $i$ in eq. (31) and $\boldsymbol{\alpha}$ is the corresponding vector of parameters. For a probit model, the marginal effect of the explanatory variable on the probability of participation is calculated as:

$$
\frac{\partial \operatorname{Prob}\left[y_{i}=1 \mid \boldsymbol{X}_{i}^{p}\right]}{\partial \boldsymbol{X}_{k i}^{P}}=\alpha_{k} f\left(\boldsymbol{\alpha}^{\prime} \boldsymbol{X}_{i}^{p}\right)
$$

Our main interest is to analyze the effect of institutional quality through trust on stock market 
participation. We compute the following marginal effects.

a) Marginal effect of a change in institutional quality of the country of residence for natives $\left(D_{N, i}=1\right)$ on stock market participation:

$$
\frac{\partial \operatorname{Prob}\left[y_{i}=1 \mid \boldsymbol{X}_{i}^{p}\right]}{\partial X_{i}^{\text {res }}}=\frac{\partial \operatorname{Prob}\left[y_{i}=1 \mid \boldsymbol{X}_{i}^{p}\right]}{\partial T_{i}^{\text {inst }}} \cdot \frac{\partial T_{i}^{\text {inst }}}{\partial X_{i}^{\text {res }}}=-a_{1} b_{N} H_{i} f\left(\boldsymbol{\alpha}^{\prime} \boldsymbol{X}_{i}^{p}\right),
$$

where

$$
H_{i}=\sum_{j=1}^{J}\left(f\left(\mu_{j}-\boldsymbol{\beta}^{\prime} \boldsymbol{X}_{i}^{T}\right)-f\left(\mu_{j-1}-\boldsymbol{\beta}^{\prime} \boldsymbol{X}_{i}^{T}\right)\right) j
$$

b) Marginal effect of a change in institutional quality of the country of residence for immigrants $\left(D_{I, i}=1\right)$ :

$$
\frac{\partial \operatorname{Prob}\left[y_{i}=1 \mid \boldsymbol{X}_{i}^{p}\right]}{\partial X_{i}^{r e s}}=\frac{\partial \operatorname{Prob}\left[y_{i}=1 \mid \boldsymbol{X}_{i}^{p}\right]}{\partial T_{i}^{i n s t}} \cdot \frac{\partial T_{i}^{i n s t}}{\partial X_{i}^{r e s}}=-a_{1} b_{I} w_{i} H_{i} f\left(\boldsymbol{\alpha}^{\prime} \boldsymbol{X}_{i}^{p}\right)
$$

c) Marginal effect of a change in institutional quality of the country of origin for immigrants $\left(D_{I, i}=1\right)$ :

$$
\begin{gathered}
\frac{\partial \operatorname{Prob}\left[y_{i}=1 \mid \boldsymbol{X}_{i}^{p}\right]}{\partial X_{i}^{\text {org }}}=\frac{\partial \operatorname{Prob}\left[y_{i}=1 \mid \boldsymbol{X}_{i}^{p}\right]}{\partial T_{i}^{\text {inst }}} \cdot \frac{\partial T_{i}^{\text {inst }}}{\partial X_{i}^{\text {org }}} \\
=-a_{1} b_{I}\left(1-w_{i}\right) H_{i} f\left(\boldsymbol{\alpha}^{\prime} \boldsymbol{X}_{i}^{p}\right) .
\end{gathered}
$$

d) Marginal effect of a change in education for immigrants $\left(D_{I, i}=1\right)$ through its effect on expected trust:

$$
\begin{gathered}
\frac{\partial \operatorname{Prob}\left[y_{i}=1 \mid \boldsymbol{X}_{i}^{p}\right]}{\partial \omega_{i}}=\frac{\partial \operatorname{Prob}\left[y_{i}=1 \mid \boldsymbol{X}_{i}^{p}\right]}{\partial T_{i}^{\text {inst }}} \cdot \frac{\partial T_{i}^{i n s t}}{\partial w_{i}} \cdot \frac{\partial \omega_{i}}{\partial A_{i}} \\
=-a_{1} b_{I}\left(X_{i}^{r e s}-X_{i}^{\text {org }}\right) H_{i} \delta_{i} f\left(\boldsymbol{\alpha}^{\prime} \boldsymbol{X}_{i}^{p}\right) \\
\delta_{i}=\frac{\partial w_{i}}{\partial A_{i}}=\frac{\gamma \exp \left(-\gamma\left(E d u_{i}-c\right)\right)}{\left(1+\exp \left(-\gamma\left(E d u_{i}-c\right)\right)\right)^{2}}
\end{gathered}
$$


See the appendix for the derivation of marginal effects.

\section{Data}

The paper is based on micro level data on individual/household characteristics and portfolio composition. The main source is the Survey of Health, Aging and Retirement in Europe (SHARE). SHARE includes comparable household-level data for people aged 50 and above in 14 European countries: Austria, Belgium, Czech Republic, Denmark, France, Germany, Greece, Ireland, Italy, Poland, the Netherlands, Spain, Sweden, and Switzerland. SHARE contains detailed information on stock market participation, wealth, income, employment, immigration background, and other demographic characteristics, etc. The advantage of using survey data as compared to actual micro data collected by statistical bureaus is that, due to the circumstance that the questionnaire is fixed, it facilitates cross-country comparisons. More importantly, as opposed to micro data, the surveys contain information about individuals' self-assessed (subjective) degree of risk aversion and trust in other people.

In the empirical estimation, we use stock market participation (i.e. stock ownership), wealth, and income of household, while household level of trust, risk aversion, and demographic attributes are assumed to be those of the household head. To select the decision maker for households with more than one possible decision maker, we first use the variable income and the person with the higher income in the household is selected as the decision maker. For households that do not report their income, we use the person with the higher education in the household as the decision maker. If neither income nor education is reported, we pick the man as the decision maker.

In the first part of the estimation, level of trust is an ordinal variable (from 0 to 10) extracted from individual answers to the following question in SHARE: 
“Generally speaking, would you say that most people can be trusted or that you can't be too careful in dealing with people?",

where 0 means that the interviewee can't be too careful and 10 means that most people can be trusted. For institutional quality in different countries, we use the index "Rule of law" 8 collected from World Bank, which "reflects perceptions of the extent to which agents have confidence in and abide by the rules of society, and in particular the quality of contract enforcement, property rights, the police, and the courts, as well as the likelihood of crime and violence." Panel A of Table 1 presents summary statistics for trust and institutional quality.

\section{[Insert Table 1]}

Panel B of Table 1 presents summary statistics for the variables used in the second part of the empirical estimation. Stock market participation is a binary variable that is equal to one if the household owns stocks and zero otherwise. The variable of risk aversion is equal to 1 if the interviewee is willing to take substantial financial risks expecting to earn substantial returns, equal to 2 if the interviewee willing to take above average financial risks expecting to earn above average returns, equal to 3 if the interviewee is willing to take average financial risks expecting to earn average returns, and equal to 4 if the interviewee not willing to take any financial risks.

In addition, we show for each country its institutional quality and the average institutional quality of its immigrants' country of origin (see Figure 1). There is a considerable difference between the two series for most of the countries. For all countries except Poland, immigration tends to be from countries with lower institutional quality. The reverse pattern in Poland depends mainly on its low institutional quality rather than the higher institutional quality of the immigrants' country of origin. Figure 2 shows the average values of trust, presenting

\footnotetext{
${ }^{8}$ For the sake of robustness, we also use the index of legal system and property rights protection from Fraser Institute as our measure of institutional quality. Our empirical results continue to hold.
} 
averages separately for natives and immigrants in each country. As seen in the figure, there are no considerable differences between average values of trust of natives as compared to immigrants. Further, Denmark has the largest mean value, followed by Sweden, Switzerland, Netherlands, and Ireland, while residents in France and Italy seem to be the most skeptical groups in our sample. We also show the rate of stock market participation in different countries (see Figure 3). The participation rate varies largely across countries. The participation rate among natives is considerably higher in Denmark and Sweden (over 35\%) than in the other countries. Sweden also has the largest rate of stock market participation among immigrants (over 25\%). Poland and the Czech Republic have the lowest participation rates $(1 \%-2 \%)$ among natives. In our sample, the immigrants in Austria, Czech Republic, Greece and Poland in our sample do not own stocks.

\section{[Insert Figure 1- Figure 3]}

\section{Empirical Analysis}

\subsection{The effect of institutional quality on trust}

We start by analyzing the impact of institutional quality on households' level of trust, by using the ordered probit models in (25) and (27). Panel A of Table 2 reports the estimates.

The first column displays the estimates of the baseline model in (25). The effects of institutional quality turn out to be positive and highly statistically significant. For immigrants, the probability of direct participation in the stock market increases with both the institutional quality of the country of residence and that of the country of origin, since $\widehat{w}$, the weight of the institutional quality of the country of residence is equal to $83.4 \%$ and significantly different from zero (see the first row in Panel B of Table 2 for the one-tailed test for $\widehat{w}$ ). This result indicates that people who have experienced a sudden change in institutional environment due to immigration do not fully adopt a level of trust that is consistent with the institutional 
quality of their new country of residence and the institutional quality of their country of origin still plays a role in their decision making. However, we can see that the institutional quality of the country of residence is more influential, as $\widehat{w}$ is larger than 0.5 at the $1 \%$ significance level (see the second row in Panel B of Table 2).

\section{[Insert Table 2]}

The model in (25) restricts the coefficients for both of the institutional quality variables for immigrants to have the same sign. For robustness, we run an ordered probit regression without any restriction on immigrants' response to the institutional quality of the country of residence and the institutional quality of the country of origin. The second column of Panel A in Table 2 reports the estimates. The parameter $b_{N}$ denotes the response of the trust level of a native resident to changes in the institutional quality of the country of residence, $b_{I}^{\text {ori }}$ is the response of the trust level of an immigrant to the institutional quality in the country of origin, and $b_{I}^{\text {res }}$ is the response of the trust level of an immigrant to the institutional quality in the country of residence. We can see that the results from the unrestricted regression agree with those from the model in (25): the effects of institutional quality are positive and significant. For people who have emigrated, the institutional qualities of both the country of residence and the country of origin have significant impact on trust. However, the institutional quality of the country of residence is more influential.

In the last column, we show the role of education in the learning process of people who have experienced a sudden change in institutions due to immigration. We use the extended model in (27), where the weight of the institutional quality of the country of residence depends on immigrants' level of education. The fact that $\hat{\gamma}$ is positive and highly significant indicates a positive relationship between education and the weight assigned to the institutional quality of immigrants' country of residence. Based on our estimates, we show the relationship between the weight and education graphically in Figure 4. The figure shows remarkable differences in 
the degree of adaptation to the new institutional environment between immigrants with lower education and those with higher education. Immigrants with no education have very low degree of adaptation, with the weight of the institutional quality of the country of residence, $(\widehat{w})$ having a value of around $25 \%$. The degree of adaptation increases sharply with education for low-educated immigrants and $\widehat{w}$ turns larger than 50\% when the level of education reaches the inflection point $\hat{c}, 4.5$ years. At the mean level of education, about 11 years education, $\widehat{w}$ is above $85 \%$. Thus, the trust of highly-educated people responds almost only to the institutional quality of country of residence.

\section{[Insert Figure 4]}

\subsection{The effect of trust on stock market participation}

In this section we show that level of trust, especially the part which is explained by institutional quality, increases the likelihood of investing in stocks. We test this by using a variety of specifications of eq. (31) with two different trust variables separately. One is the ordinal trust variable extracted from the survey data; the other is the expected trust of individuals conditional on institutional quality, which we calculate as described in eq. (30) using the estimates of the model in (27). Table 3 presents the results.

The first columns of Panels A and B in Table 3 report the results for the specification without control variables. The effects of both trust variables are positive and highly statistically significant. Further, we can see that the expected trust variable has a better explanatory power than the trust variable extracted from the survey, as the $t$ value of the former is twice that of the latter. The Akaike information criteria of the regressions also suggest a better explanatory power of the expected trust variable.

\section{[Insert Table 3]}

We control for a variety of individual characteristics that have been shown to affect 
participation by previous studies and report the results in column two and three in Panel A and B. In the second specification, we control for household income, household wealth, years of education, marriage and birth year. In the third specification, we also control for risk aversion. The effects of both trust variables are robust to the choices of control variables: they are positive and highly significant in all specifications. The $t$ values for the trust variables and Akaike information criteria of the regressions suggest that expected trust has a better capability than the raw measure of trust from the survey in explaining stock market participation, regardless of the choices of control variables. Thus, we can conclude that trust, especially the part of which is explained by institutional quality, increases the likelihood of participating in the stock market.

The control variables mostly display the expected signs. Income, wealth, years of education, the status of being married are all positively related to participation. In the third specification, the effect of risk aversion is negative and highly significant. The effect of wealth becomes insignificant when risk aversion is inserted, which suggests that the effect of wealth is captured by risk aversion. The effect of year of birth is not significant except for being significantly negative in the specification with the trust from the survey and risk aversion.

\subsection{The effect of institutional quality on stock market participation through the effect of trust}

In Sections 5.1 and 5.2, we demonstrate that institutional quality significantly affects trust and the level of trust that is related to institutional quality in turn has a significant effect on the probability of stock market participation. In this section, we connect the results from the previous two sections and study the effect of institutional quality on stock market participation through its effect on trust. Based on the estimates of eq. (27) and eq. (31), we calculate the marginal effects of institutional quality on the likelihood of investing in stocks (see eq. (34)-(36)). Table 4 reports the marginal effects at the sample means of the data, 
except for the marriage dummy at value zero. It shows that a unit increase in institutional quality will increase a native household's probability of investing in stocks by 16 percentage points. The increase for immigrants is 6.1 percentage points and 1.3 percentage points, respectively, where the first number corresponds to a unit increase in the institutional quality of country of residence and the second number corresponds to a unit increase in that of country of origin. Thus, it appears that increases in institutional quality have a larger effect on natives' stock market participation than that of immigrants. Most likely, this result reflects the circumstance that for immigrants, there are other important determinants of stock market participation, besides institutional quality.

\section{[Insert Table 4]}

Furthermore, we investigate the role of education in households' likelihood of owning stocks. According to our modeling, the impact of education on participation has two channels: the first one being that people with higher education tend to be more financially sophisticated and thus are more likely to own risky assets. This direct effect is captured by education as a control variable in the model in (31). The other channel, which pertains to people who have emigrated, is that education affects participation indirectly through its effect on the degree of adaptation to the new institutional environment. The last row of Table 4 shows the indirect effects of education on stock market participation, calculated as described in eq. (37). A one year increase in education will indirectly increase the probability of participation by 0.2 percentage points, as compared to the direct effect that results in a 0.8 percentage point increase. That is, although the indirect effect is not the most important one, it is by no means negligible.

Education increases the degree of adaptation to the new institutional environment, which in turn affects stock market participation. Figure 5 shows the marginal effect of institutional quality on participation at different levels of education (from no education to 25 years of 
education). ${ }^{9}$ As expected, the impact of the institutional quality of the country of residence increases with education. However, the impact of the institutional quality of the country of origin decreases with higher education after the time spent on education has reached five years. This can be explained by the fact that education not only affects participation through the formation of trust, but also directly as a control variable. ${ }^{10}$ For households with very low education, participation is influenced to a large extent by experiences in the home country. The effect of the institutional quality of the country of residence surpasses that of home country if the household head has five or more years of education. Furthermore, the institutional quality of country of origin has only a negligible effect on the participation of the most highly-educated immigrants, which is in line with the notion that for the most highly-educated immigrants, adaptation requires much less effort.

[Insert Figure 4]

\section{Conclusion}

In this paper, we analyze the effects of institutional quality on stock market participation, both theoretically and empirically. We develop a theoretical model in which institutional quality affects trust through learning. We model agents as Bayesian updaters who from time to time observe frauds. In the model, higher institutional quality is likely to lead to a higher level of trust, and for a sufficiently high level of trust, agents want to invest in the stock market. Immigrants who emigrate from a country of lower institutional quality tend to have lower trust, which in turn means that they tend to be less prone to participate in the stock market. This effect is more pronounced the lower the education of the immigrants, and the lower the institutional quality of their country of origin.

\footnotetext{
${ }^{9}$ The values of all variables but education are fixed. The values of the binary variables, married and male, are fixed at 0 , while the values of others are fixed at the sample means.

${ }^{10}$ In eq. (36), education enters in $\mathrm{w}_{\mathrm{i}}$ as well as in $\mathrm{f}\left(\alpha^{\prime} \mathrm{X}_{\mathrm{i}}^{\mathrm{p}}\right)$.
} 
Based on our theoretical model, we build an empirical model by which we investigate the degree to which stock market participation is affected by households' level of trust, which in turn is affected by institutional quality. Using European survey data (the SHARE data set), covering more than 30,000 individuals in fourteen European countries, and a measure of institutional quality from the World Bank, we find strong support for our hypotheses: institutional quality has a significant effect on individuals' level of trust and trust (especially that which is explained by institutional quality) in turn significantly affects the probability of stock market participation. In addition, we find that immigrants are affected by the institutional quality of not only their country of residence but also their country of origin. The more time the immigrants have spent on education, the larger is the impact of the institutional quality of the country of residence. This result is in line with the notion that highly educated immigrants need to exert less effort in order to learn about their new institutional environment. 


\section{References}

Allen, F. and D. Gale (1994). Limited market participation and volatility of asset prices. American Economic Review 84, 933-955.

Ang, A., G. Bekaert and J. Liu (2005). Why stocks may disappoint. Journal of Financial Economics 76, 471-508.

Bohnet, I. and H. Steffen (2004). Repetition and reputation: Implications for trust and trustworthiness when institutions change. American Economic Review 94, 362-366.

Brown, J. R., Z. Ivković, P. A. Smith and S. Weisbenner (2008). Neighbors matter: Causal community effects and stock market participation. Journal of Finance 63, 1509-1531.

Cao, H., T.Wang and H. H. Zhang (2005). Model uncertainty, limited market participation, and asset prices. Review of Financial Studies 18, 1219-1251.

Christelis, D., D. Georgarakos and M Haliassos (2013). Differences in portfolios across countries: Economic environment versus household characteristics. Review of Economics and Statistics 95, 220-236.

Dow, J. and S. Werlang (1992). Uncertainty aversion, risk aversion and the optimal choice of portfolio. Econometrica 60, 197-204.

Epstein, L. and M. Schneider (2007). Learning under ambiguity. Review of Economic Studies $74,1275-1303$.

Georgarakos, D. and G. Pasini (2011). Trust, sociability, and stock market participation. Review of Finance 15, 693-725.

Gomes, F. J. (2005). Portfolio choice and trading volume with loss-averse investors. Journal of Business 78, 675-706

Guiso, L., S. Paola and L. Zingales (2004). The role of social capital in financial development. American Economic Review 94, 526-556.

Guiso, L., P. Sapienza and L. Zingales (2008). Trusting the stock market. Journal of Finance, $63,2557-2600$.

Hakansson, N. (1971). On optimal myopic portfolio policies, with and without serial correlation of yields. Journal of Business 44, 324-334. 
Hong, H., J. D. Kubik and J. C. Stein (2004). Social interaction and stock-market participation. Journal of Finance 59, 137-163.

Mossin, J. (1968). Optimal multiperiod portfolio policies. Journal of Business 44, 215-229.

Osili, U. O. and A. L. Paulson (2008a). What can we learn about financial access from US immigrants? The role of country of origin institutions and immigrant beliefs. World Bank Economic Review 22, 431-455.

Osili, U. O. and A. L. Paulson (2008b). Institutions and financial development: Evidence from international migrants in the United States. Review of Economics and Statistics 90, 498-517.

Williamson, S. (1994). Liquidity and market participation. Journal of Economic Dynamics and Control 18, 629-670. 


\section{Table 1 Summary statistics}

The table shows summary statistics of the variables we use. Panel A and Panel B present the variables we used in the first and the second parts of the estimation, respectively. All variables except institutional quality are from the Survey Health, Ageing, and Retirement in Europe. Trust is an index variable (from 0 to 10); an answer to the question "Generally speaking, would you say that most people can be trusted or that you can't be too careful in dealing with people?", where 0 means the household head can't be too careful and 10 means that most people can be trusted by the household head. Participation is a binary variable, equal to one if the household owns stocks and zero otherwise. Risk aversion is elicited from answers to a question regarding the amount of financial risk that the household head is willing to take. It is equal to 1 if the household head is willing to take substantial financial risks expecting to earn substantial returns, equal to 2 if the household head willing to take above average financial risks expecting to earn above average returns, equal to 3 if the household head willing to take average financial risks expecting to earn average returns, and equal to 4 if the household head not willing to take any financial risks. Institutional quality is the Rule of law variable collected from the World Bank.

\begin{tabular}{|c|c|c|c|c|c|}
\hline & Mean & Median & Std. Dev. & Minimum & Maximum \\
\hline \multicolumn{6}{|c|}{$\begin{array}{l}\text { Panel A. The first part of the estimation } \\
\text { Number of native-borns }=18932 ; \text { Number of immigrants }=1330\end{array}$} \\
\hline Trust & 5.61 & 6.00 & 2.53 & 0 & 10 \\
\hline Inst. Qual. Residence & 1.31 & 1.45 & 0.51 & 0.40 & 1.95 \\
\hline Inst. Qual. Origin & 0.71 & 0.75 & 0.98 & -2.32 & 1.99 \\
\hline \multicolumn{6}{|c|}{$\begin{array}{l}\text { Panel B. The second part of the estimation } \\
\qquad \mathrm{N}=7931\end{array}$} \\
\hline Participation & 0.15 & 0.00 & 0.35 & 0 & 1 \\
\hline Income & $1.0 \mathrm{E}+04$ & $1.6 \mathrm{E}+03$ & $2.3 \mathrm{E}+04$ & 9 & $6.7 \mathrm{E}+05$ \\
\hline Wealth & $1.4 \mathrm{E}+06$ & $7.3 \mathrm{E}+04$ & $2.3 \mathrm{E}+07$ & $-1.2 \mathrm{E}+06$ & $1.1 \mathrm{E}+09$ \\
\hline Years of Education & 10.86 & 11.00 & 4.31 & 0 & 25 \\
\hline Birth Year & 1940 & 1941 & 10.40 & 1908 & 1978 \\
\hline Married & 0.48 & 0.00 & 0.50 & 0 & 1 \\
\hline Male & 0.58 & 1.00 & 0.49 & 0 & 1 \\
\hline Risk Aversion & 3.65 & 4.00 & 0.66 & 1 & 4 \\
\hline
\end{tabular}




\section{Table 2 Institutional quality explaining level of trust: unrestricted model}

The table shows the results for ordered probit regressions of trust at the individual level on institutional quality at the country level (i.e. the Rule of law variable from the World Bank). The first column of Panel A shows the estimates of equation (25). $b_{I}$ is the response of the trust level of an immigrant to the weighted average of institutional quality in the country of residence and institutional quality in the country of origin, $w$ is the weight assigned to country of residence. The second column shows the results for the unrestricted model $T_{i}^{*}=b_{0}+$ $b_{N} D_{N, i} X_{i}^{\text {res }}+b_{I}^{\text {ori }} D_{I, i} X_{i}^{\text {ori }}+b_{I}^{\text {res }} D_{I, i} X_{i}^{\text {res }}+\varepsilon_{i}$, where $b_{N}$ is the response of the trust level of a native resident to changes in the institutional quality of the country of residence, $b_{I}^{\text {ori }}$ is the response of the trust level of an immigrant to changes in the institutional quality of the country of origin and $b_{I}^{\text {res }}$ is the response of the trust level of an immigrant to changes in the institutional quality of the country of residence. The last column consists of estimates from equation (27), where $w=\frac{1}{1+\exp (-\gamma(E d u-c))}$ and $E d u$ is the household head's years of education. Standard errors are in parentheses. ${ }^{* * *},{ }^{* *}$ and ${ }^{*}$ indicate significance at the $1 \%, 5 \%$ and $10 \%$ levels, respectively. Panel B reports the results of our hypothesis testing regarding the value on $\widehat{w}$ in eq. (27).

Panel A. (N=20262)

\begin{tabular}{lccc} 
& Restr. (eq (25)) & Unrestr. & Restr.with Edu. (eq. (27)) \\
\hline$b_{N}$ & $0.442^{* * * *}$ & $0.442^{* * *}$ & $0.441^{* * * *}$ \\
& $(0.014)$ & $(0.014)$ & $(0.014)$ \\
$b_{I}$ & $0.345^{* * *}$ & & $0.352^{* * * *}$ \\
& $(0.027)$ & & $(0.025)$ \\
$w$ & $0.834^{* * *}$ & & \\
\multirow{2}{*}{$b_{I}^{\text {ori }}$} & $(0.078)$ & & \\
& & $0.057^{*}$ & \\
$b_{I}^{\text {res }}$ & & $(0.029)$ & \\
& & $0.289^{* * *}$ & \\
& & $(0.026)$ & \\
$\gamma$ & & & $0.241^{* *}$ \\
$c$ & & & $(0.103)$ \\
& & & $4.507^{*}$ \\
& & & $(2.385)$ \\
\hline
\end{tabular}

Panel B. Hypothesis testing regarding the value on $\widehat{w}$ in eq. (27)

\begin{tabular}{lll}
\hline H0 & H1 & p-value \\
$\widehat{w}=1$ & $\widehat{w}<1$ & 0.017 \\
$\widehat{w}=0.5$ & $\widehat{w}>0.5$ & 0.000 \\
\hline
\end{tabular}




\section{Table 3 Explaining stock market participation}

The table reports the results for probit regressions of stock market participation on trust. Specification M1 does not have control variables. Specification M2 controls for household income, wealth, years of education and birth year of household head, and marriage status. Specification M3 controls for everything in M2 and self-assessed level of risk aversion. In Panel A, the trust variable is the self-assessed level of trust extracted from the SHARE survey data. In Panel B, the trust variable is the part of trust explained by institutional qualities, which is calculated according to eq. (30), based on estimates of eq. (27). The last column of Panel B displays the marginal effect of the variables in specification M3.

\begin{tabular}{|c|c|c|c|c|c|c|c|}
\hline & \multicolumn{3}{|c|}{ Panel A: Trust $(N=7931)$} & \multicolumn{4}{|c|}{ Panel B: Expected Trust $(\mathrm{N}=7931)$} \\
\hline & M1 & M2 & M3 & M1 & M2 & M3 & $\begin{array}{l}\text { Marginal } \\
\text { effect (M3) }\end{array}$ \\
\hline Trust & $\begin{array}{l}0.094^{* * *} \\
(0.007)\end{array}$ & $\begin{array}{l}0.076^{\text {*** }} \\
(0.008)\end{array}$ & $\begin{array}{l}0.065^{* * *} \\
(0.008)\end{array}$ & & & & \\
\hline $\begin{array}{l}\text { Expected } \\
\text { trust }\end{array}$ & & & & $\begin{array}{l}1.076^{* * *} \\
(0.044)\end{array}$ & $\begin{array}{l}1.034^{* * *} \\
(0.047)\end{array}$ & $\begin{array}{l}0.937^{* * *} \\
(0.048)\end{array}$ & $0.143^{* * *}$ \\
\hline Income & & $\begin{array}{l}4.2 \mathrm{E}-06^{* * *} \\
(6.6 \mathrm{E}-07)\end{array}$ & $\begin{array}{l}3.1 \mathrm{E}-06^{* * *} \\
(6.9 \mathrm{E}-07)\end{array}$ & & $\begin{array}{l}1.9 \mathrm{E}-06^{* * *} \\
(6.9 \mathrm{E}-07)\end{array}$ & $\begin{array}{l}1.2 \mathrm{E}-06^{*} \\
(7.2 \mathrm{E}-07)\end{array}$ & $1.8 \mathrm{E}-07^{*}$ \\
\hline Wealth & & $\begin{array}{l}1.2 \mathrm{E}-09^{* *} \\
(5.8 \mathrm{E}-10)\end{array}$ & $\begin{array}{l}9.7 \mathrm{E}-10 \\
(6.1 \mathrm{E}-10)\end{array}$ & & $\begin{array}{l}1.0 \mathrm{E}-09^{*} \\
(5.9 \mathrm{E}-10)\end{array}$ & $\begin{array}{l}8.7 \mathrm{E}-10 \\
(6.1 \mathrm{E}-10)\end{array}$ & $1.3 \mathrm{E}-10$ \\
\hline Education & & $\begin{array}{l}0.072^{* * * *} \\
(0.005)\end{array}$ & $\begin{array}{l}0.060^{* * *} \\
(0.005)\end{array}$ & & $\begin{array}{l}0.064^{* * *} \\
(0.005)\end{array}$ & $\begin{array}{l}0.053^{* * *} \\
(0.005)\end{array}$ & $0.008^{* * *}$ \\
\hline Birth year & & $\begin{array}{l}-0.003 \\
(0.002)\end{array}$ & $\begin{array}{l}-0.008^{* * *} \\
(0.002)\end{array}$ & & $\begin{array}{l}0.002 \\
(0.002)\end{array}$ & $\begin{array}{l}-0.003 \\
(0.002)\end{array}$ & $-4.9 \mathrm{E}-04$ \\
\hline Married & & $\begin{array}{l}0.285^{* * *} \\
(0.043)\end{array}$ & $\begin{array}{l}0.270^{* * *} \\
(0.045)\end{array}$ & & $\begin{array}{l}0.334^{* * *} \\
(0.046)\end{array}$ & $\begin{array}{l}0.309^{* * *} \\
(0.047)\end{array}$ & $0.048^{* * *}$ \\
\hline Male & & $\begin{array}{l}0.202^{* * *} \\
(0.045)\end{array}$ & $\begin{array}{l}0.126^{* * *} \\
(0.047)\end{array}$ & & $\begin{array}{l}0.209^{* * *} \\
(0.048)\end{array}$ & $\begin{array}{l}0.133^{* * *} \\
(0.049)\end{array}$ & $0.020^{* * *}$ \\
\hline $\begin{array}{l}\text { Risk } \\
\text { aversion }\end{array}$ & & & $\begin{array}{l}-0.578^{* * *} \\
0.025\end{array}$ & & & $\begin{array}{l}-0.527^{* * *} \\
(0.026)\end{array}$ & $-0.080^{* * * *}$ \\
\hline $\log \mathrm{L}$. & -3233 & -2943 & -2682 & -2909 & -2682 & -2480 & \\
\hline Pseudo R2 & 0.026 & 0.113 & 0.192 & 0.123 & 0.192 & 0.253 & \\
\hline AIC & 6480 & 5901 & 5379 & 5833 & 5378 & 4975 & \\
\hline
\end{tabular}


Table 4 Marginal effect of institutional quality and education through the channel of trust

The table shows the marginal effect of institutional quality on stock market participation through the channel of trust for native-borns and immigrants respectively. $X^{\text {res }}$ is the variable of institutional quality in the country of residence, $X^{\text {org }}$ the variable of institutional quality in the country of origin for immigrants. The last row shows the marginal effect of education on stock market participation through the channel of trust for immigrants.

\begin{tabular}{lll}
\hline Native-born & $X^{\text {res }}$ & $16.0 \%$ \\
\hline Immigrant & $X^{\text {org }}$ & $1.3 \%$ \\
& $X^{\text {res }}$ & $6.1 \%$ \\
& Edu. (through trust) & $0.2 \%$ \\
\hline
\end{tabular}


Figure 1. Institutional quality of the countries in the sample

The figure shows the institutional quality of the countries in the sample, and for each country it also shows the average institutional quality of its immigrants' country of origin. The last two bars show the averages over all countries.

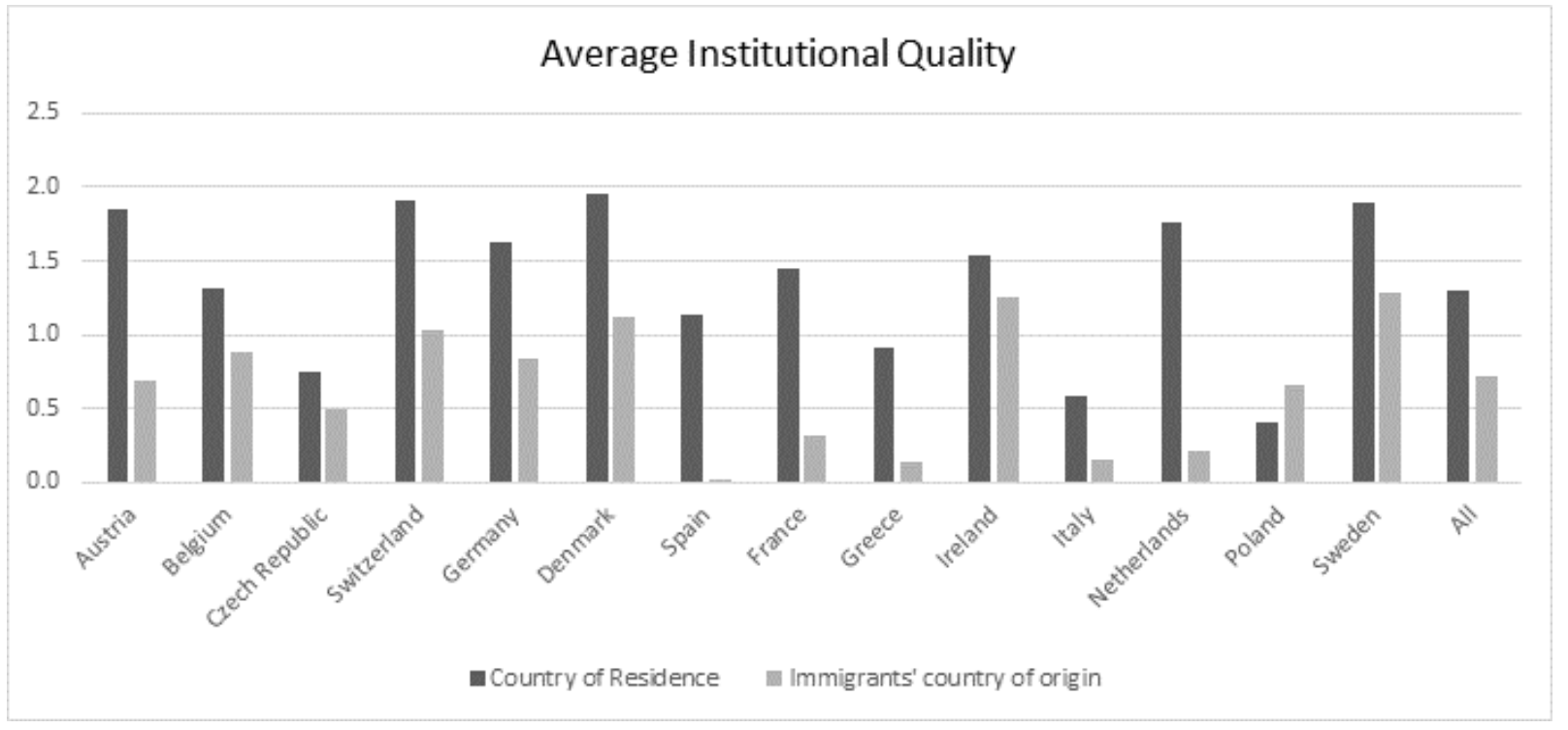




\section{Figure 2. Average value of the trust variable}

The figure shows the average values of the individual self-assessed level of trust for different countries. The trust variable ranges between zero and ten, where zero corresponds to the lowest level of trust. The averages are calculated separately for natives and immigrants in each country. The last two bars show the average values for all countries.

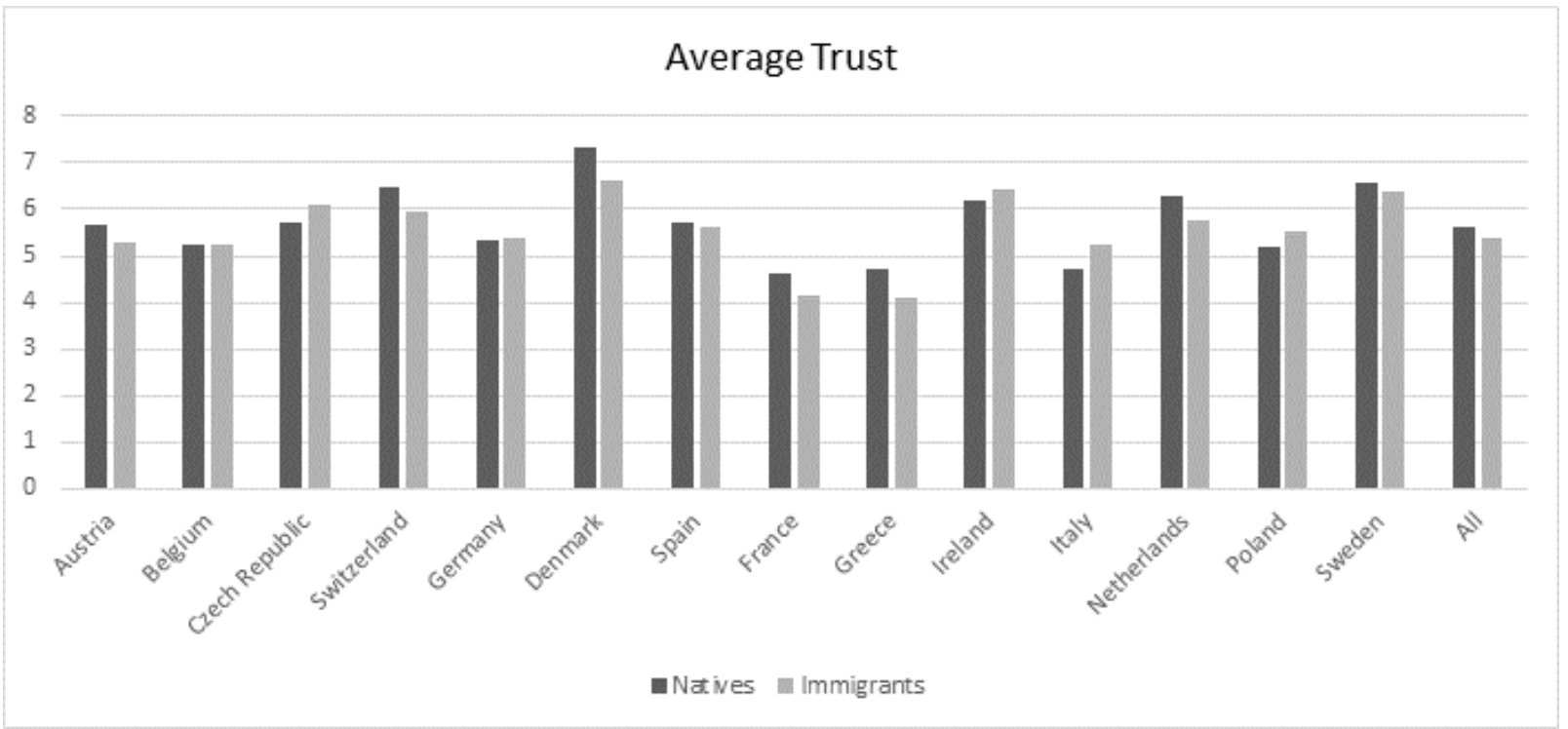


Figure 3. Average rate of stock market participation in the sample

The figure shows the average rate of stock market participation across countries. The averages are calculated separately for natives and immigrants in each country. The last two bars show the average values over all the countries.

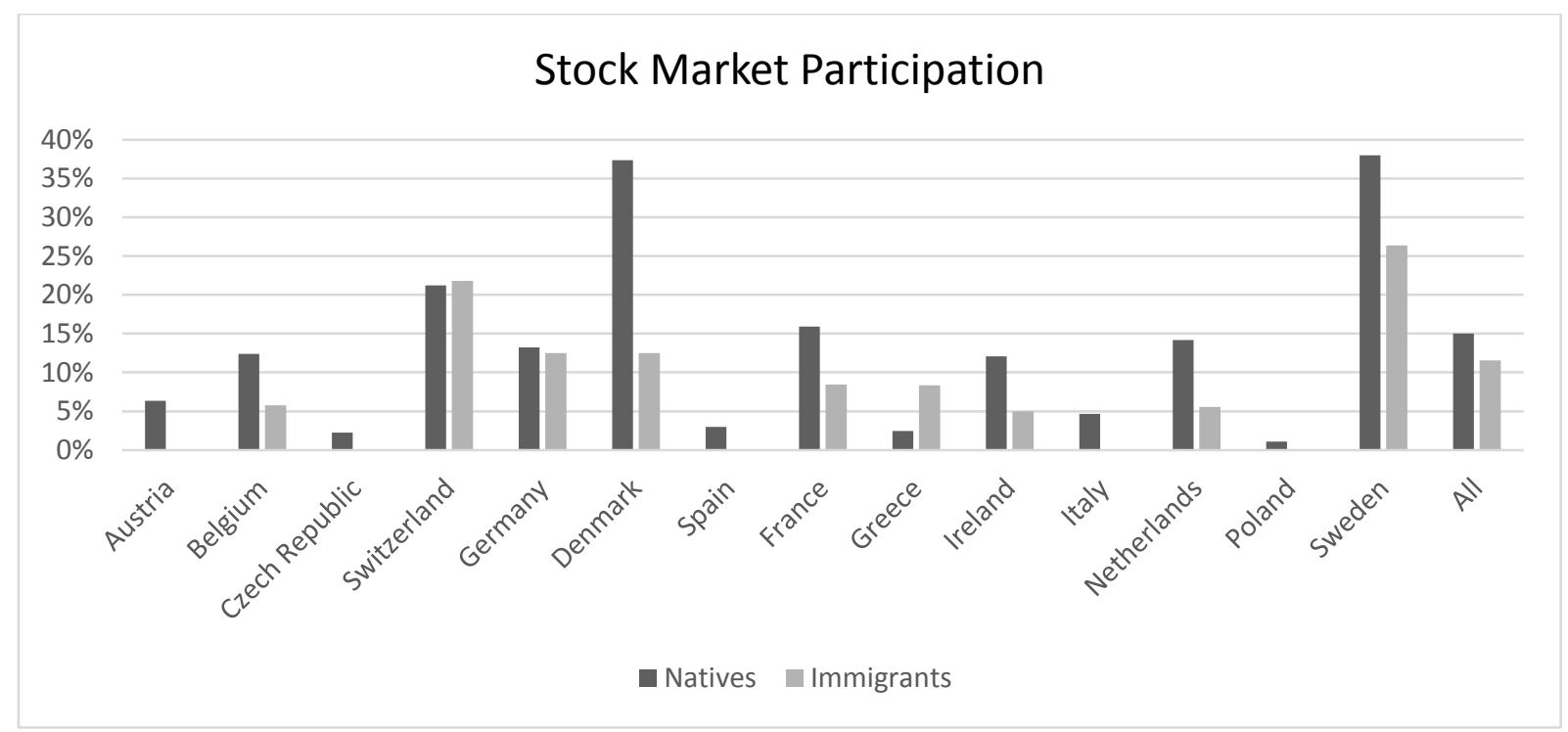


Figure 4. The relative importance of institutional quality of country of residence for immigrants' level of trust

The figure shows the importance (weight) of institutional quality of country of residence for immigrants' level of trust, relative to that of institutional quality of country of origin, at different levels of education. The importance (weight) of institutional quality of country of residence is calculated as a function of education $\mathrm{w}=\frac{1}{1+\exp (-\gamma(\operatorname{Edu}-\mathrm{c}))}$, where Edu is the years of education. Estimates for $\gamma$ and c are reported in Table 2.

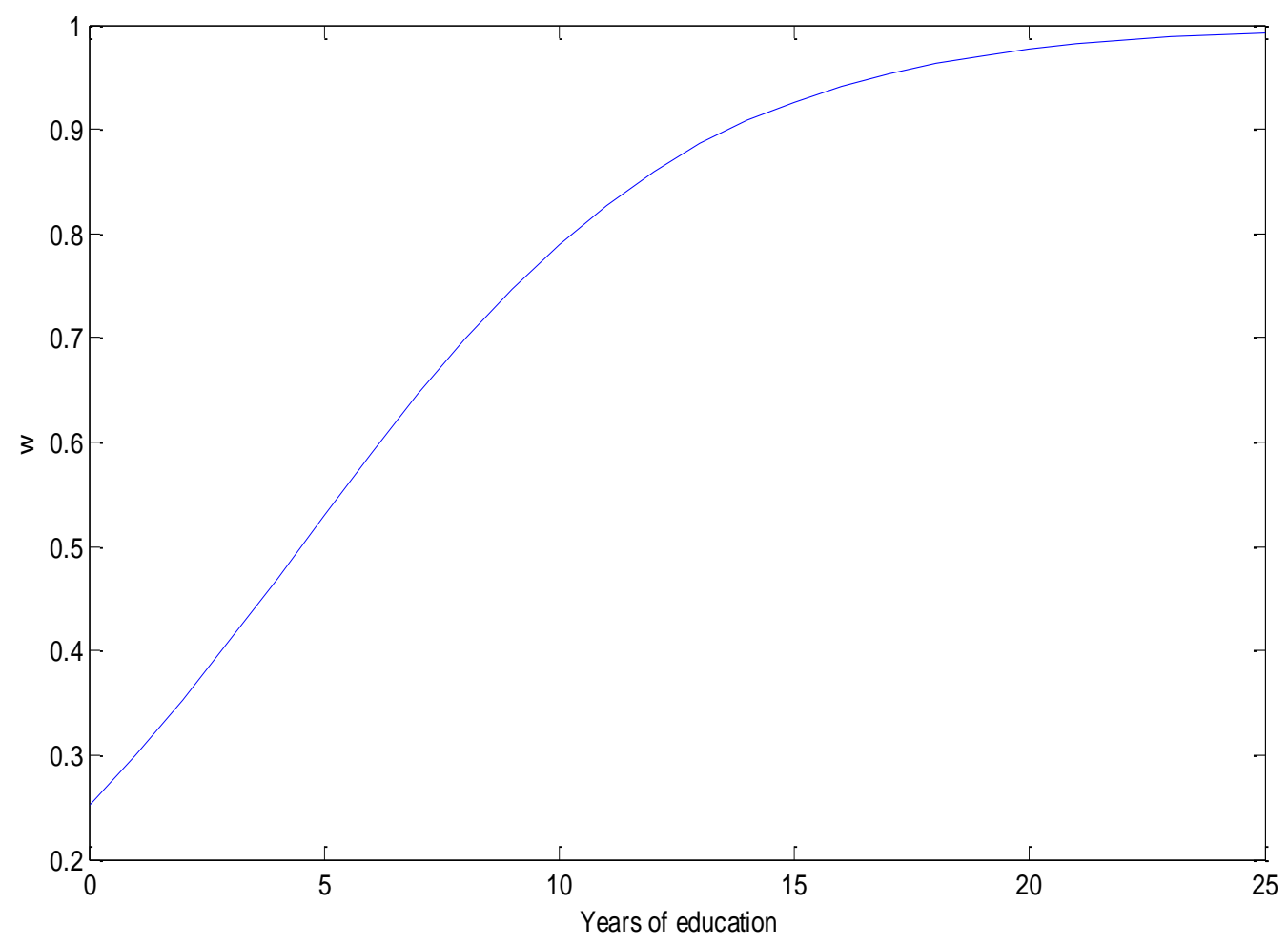


Figure 5: Marginal effect of institutional qualities on immigrants' stock market participation

The figure shows the marginal effects of institutional qualities in country of origin and country of residence on immigrants' stock market participation through the channel of trust at different levels of education. All variables are fixed at the sample mean, except that the marriage dummy is at value zero and the variable of years of education varies from 0 to 25 .

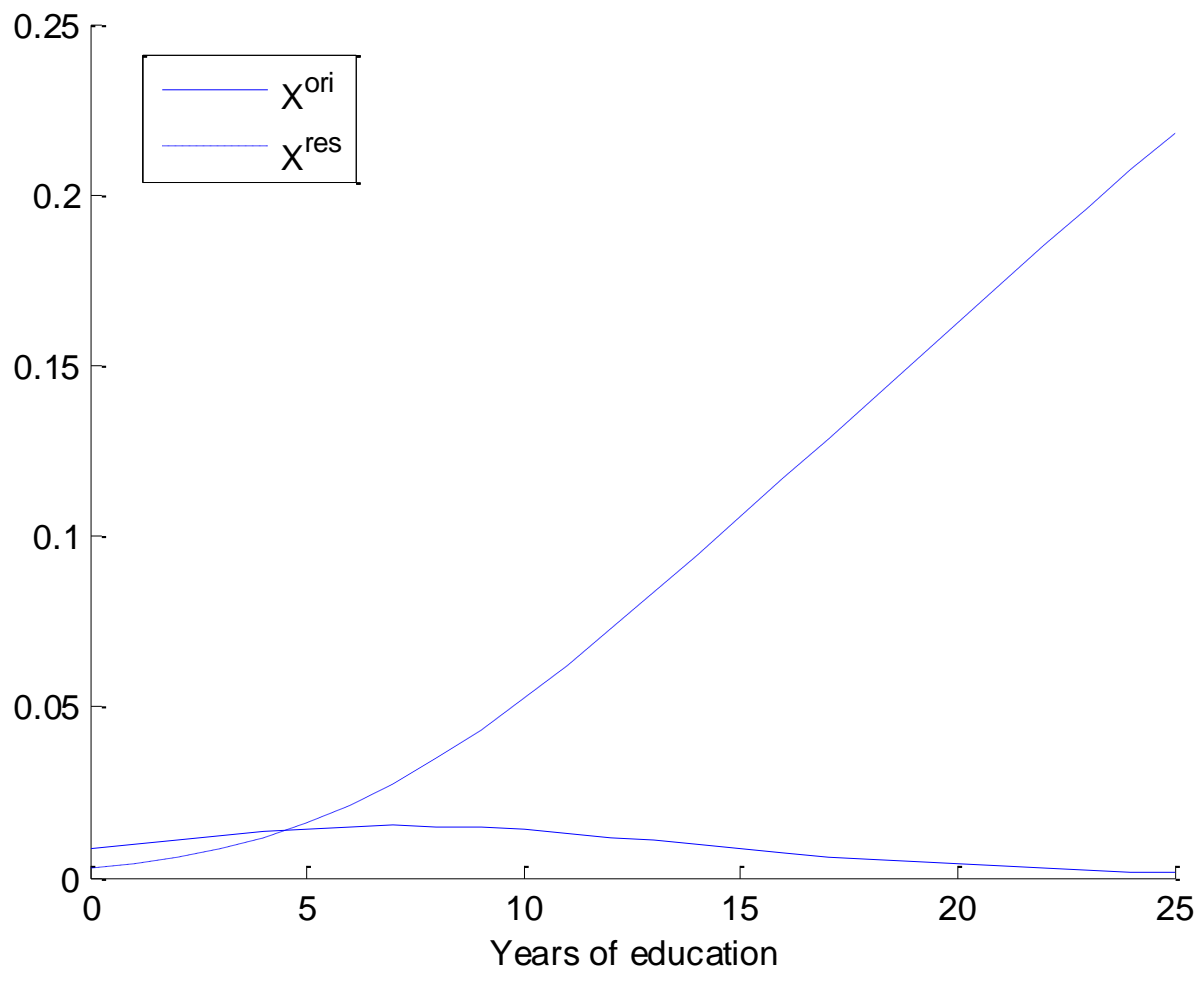




\section{Appendix A}

\section{A.1 Condition for myopic investors' stock market participation}

Here, we study the investment problem of a myopic investor and we show that the condition in (8) also applies to any myopic investor with strictly increasing, strictly concave and twicecontinuously differentiable elementary utility function $u$ satisfying $\lim _{W \rightarrow 0} u^{\prime}(W)=+\infty$. Consider such an investor's objective function at time $t$ (where we have inserted the wealth constraints and use notation consistent with the one in the main text):

$$
\begin{aligned}
& g_{t}\left(\alpha_{t}\right) \equiv \operatorname{Prob}\left(\tilde{R}_{t+1}=\varepsilon \mid D_{t}\right) u\left(W_{t}\left(R_{f}+\alpha_{t}\left(\varepsilon-R_{f}\right)\right)\right) \\
& \quad+\left(1-\operatorname{Prob}\left(\tilde{R}_{t+1}=\varepsilon \mid D_{t}\right)\right) E_{t}\left[u\left(W_{t}\left(R_{f}+\alpha_{t}\left(\tilde{R}_{t+1}^{+}-R_{f}\right)\right)\right)\right] .
\end{aligned}
$$

The investor also faces a no short-selling constraint, $\alpha_{t} \geq 0$.

The first- and second-order derivatives with respect to $\alpha_{t}$ are given by

$$
\begin{gathered}
g_{t}{ }^{\prime}\left(\alpha_{t}\right)=\operatorname{Prob}\left(\tilde{R}_{t+1}=\varepsilon \mid D_{t}\right) u^{\prime}\left(W_{t}\left(R_{f}+\alpha_{t}\left(\varepsilon-R_{f}\right)\right)\right) W_{t}\left(\varepsilon-R_{f}\right) \\
+\left(1-\operatorname{Prob}\left(\tilde{R}_{t+1}=\varepsilon \mid D_{t}\right)\right) E_{t}\left[u^{\prime}\left(W_{t}\left(R_{f}+\alpha_{t}\left(\tilde{R}_{t+1}^{+}-R_{f}\right)\right)\right) W_{t}\left(\tilde{R}_{t+1}^{+}-R_{f}\right)\right] \\
g_{t}{ }^{\prime \prime}\left(\alpha_{t}\right)=\operatorname{Prob}\left(\tilde{R}_{t+1}=\varepsilon \mid D_{t}\right) u^{\prime \prime}\left(W_{t}\left(R_{f}+\alpha_{t}\left(\varepsilon-R_{f}\right)\right)\right) W_{t}^{2}\left(\varepsilon-R_{f}\right)^{2} \\
+\left(1-\operatorname{Prob}\left(\tilde{R}_{t+1}=\varepsilon \mid D_{t}\right)\right) E_{t}\left[u^{\prime \prime}\left(W_{t}\left(R_{f}+\alpha_{t}\left(\tilde{R}_{t+1}^{+}-R_{f}\right)\right)\right) W_{t}^{2}\left(\tilde{R}_{t+1}^{+}-R_{f}\right)^{2}\right] .
\end{gathered}
$$

Since $u$ is strictly concave, $g_{t}{ }^{\prime \prime}\left(\alpha_{t}\right)<0$ for all $\alpha_{t}$, i.e., $g_{t}$ is strictly concave in $\alpha_{t}$. Therefore, the investor will participate in the stock market $\left(\alpha_{t}^{*}>0\right)$ if and only if $g_{t}{ }^{\prime}(0)>0$, i.e., if and only if

$$
\operatorname{Prob}\left(\tilde{R}_{t+1}=\varepsilon \mid D_{t}\right) u^{\prime}\left(W_{t} R_{f}\right) W_{t}\left(\varepsilon-R_{f}\right)
$$




$$
+\left(1-\operatorname{Prob}\left(\tilde{R}_{t+1}=\varepsilon \mid D_{t}\right)\right) u^{\prime}\left(W_{t} R_{f}\right) W_{t} E_{t}\left[\tilde{R}_{t+1}^{+}-R_{f}\right]>0 .
$$

The above condition is equivalent to the one in (8).

\section{A.2 Participation costs}

In line with Guiso, Sapienza and Zingales (2008), we now introduce a fixed cost of participation in the stock market, $f$. That is, wealth is decreased by $f$ if the investor invests in the stock market. This induces wealth effects which interact with trust. Guiso, Sapienza and Zingales (2008) show that a small probability of fraud substantially increases the level of wealth required for stock market participation. Unless stated otherwise, we assume that $\xi_{t}>$ $\operatorname{Prob}\left(\tilde{R}_{t+1}=\varepsilon \mid D_{t}\right) /\left(1-\operatorname{Prob}\left(\tilde{R}_{t+1}=\varepsilon \mid D_{t}\right)\right)$, so that the investor would participate in the stock market in the absence of participation costs (see Equation 8 in Section 2 and also Appendix A.1). Defining the certainty equivalent stock return $\hat{R}_{t}$ implicitly through the relation

$$
\begin{gathered}
\operatorname{Prob}\left(\tilde{R}_{t+1}=\varepsilon \mid D_{t}\right) u\left(\left(W_{t}-f\right)\left(R_{f}+\alpha_{t}^{*}\left(\varepsilon-R_{f}\right)\right)\right) \\
+\left(1-\operatorname{Prob}\left(\tilde{R}_{t+1}=\varepsilon \mid D_{t}\right)\right) E_{t}\left[u\left(\left(W_{t}-f\right)\left(R_{f}+\alpha_{t}^{*}\left(\tilde{R}_{t+1}^{+}-R_{f}\right)\right)\right)\right]= \\
u\left(\left(W_{t}-f\right)\left(R_{f}+\alpha_{t}^{*}\left(\hat{R}_{t}-R_{f}\right)\right)\right),
\end{gathered}
$$

where $\alpha_{t}^{*}$ is the optimal fraction of wealth allocated to the stock in the absence of participation costs if wealth is $\left(W_{t}-f\right)$, we can express the threshold level of wealth in terms of this quantity, as shown in the following proposition. Because of the assumption that $\xi_{t}>$ $\operatorname{Prob}\left(\tilde{R}_{t+1}=\varepsilon \mid D_{t}\right) /\left(1-\operatorname{Prob}\left(\tilde{R}_{t+1}=\varepsilon \mid D_{t}\right)\right), \alpha_{t}^{*}$ is strictly positive. 
Proposition 1: There exists a threshold level of wealth above which the investor will participate in the stock market. This threshold level of wealth is given by

$$
\bar{W}_{t}=f \frac{R_{f}+\alpha_{t}^{*}\left(\hat{R}_{t}-R_{f}\right)}{\alpha_{t}^{*}\left(\hat{R}_{t}-R_{f}\right)}
$$

where $\hat{R}_{t}$ is defined implicitly through equation (A4).

Proof: At the threshold value of wealth, we have that

$$
\begin{aligned}
& \operatorname{Prob}\left(\tilde{R}_{t+1}=\varepsilon \mid D_{t}\right) u\left(\left(\bar{W}_{t}-f\right)\left(R_{f}+\alpha_{t}^{*}\left(\varepsilon-R_{f}\right)\right)\right) \\
& +\left(1-\operatorname{Prob}\left(\tilde{R}_{t+1}=\varepsilon \mid D_{t}\right)\right) E_{t}\left[u\left(\left(\bar{W}_{t}-f\right)\left(R_{f}+\alpha_{t}^{*}\left(\tilde{R}_{t+1}^{+}-R_{f}\right)\right)\right)\right]=u\left(\bar{W}_{t} R_{f}\right),
\end{aligned}
$$

and thus,

$$
u\left(\left(\bar{W}_{t}-f\right)\left(R_{f}+\alpha_{t}^{*}\left(\hat{R}_{t}-R_{f}\right)\right)\right)=u\left(\bar{W}_{t} R_{f}\right)
$$

The result then follows from the strict monotonicity of $u$.

The above proposition shows that participation costs induce wealth effects and we determine the threshold level of wealth required for stock market participation. More interestingly, as we show in the following proposition, the learning mechanism interacts with the participation costs in such a way that having a nonzero prior probability of fraud increases the threshold value of wealth required for stock market participation.

Proposition 2: The higher the prior probability of fraud, the higher the threshold value of wealth required for stock market participation.

Proof: Suppose that $\overline{\bar{\theta}}_{0}>\bar{\theta}_{0}$ and suppose also that $\bar{W}_{t}$ is the threshold value of wealth corresponding to the lower prior $\left(\bar{\theta}_{0}\right)$, meaning that 


$$
\begin{aligned}
& \operatorname{Prob}\left(\tilde{R}_{t+1}=\varepsilon \mid D_{t} ; \bar{\theta}_{0}\right) u\left(\left(\bar{W}_{t}-f\right)\left(R_{f}+\alpha_{t}^{*}\left(\varepsilon-R_{f}\right)\right)\right) \\
& +\left(1-\operatorname{Prob}\left(\tilde{R}_{t+1}=\varepsilon \mid D_{t} ; \bar{\theta}_{0}\right)\right) E_{t}\left[u\left(\left(\bar{W}_{t}-f\right)\left(R_{f}+\alpha_{t}^{*}\left(\tilde{R}_{t+1}^{+}-R_{f}\right)\right)\right)\right]=u\left(\bar{W}_{t} R_{f}\right) .
\end{aligned}
$$

With a higher prior probability of fraud, the expected utility that can, ceteris paribus, be achieved in the absence of participation costs when wealth is $\left(W_{t}-f\right)$ must be lower:

$$
\begin{aligned}
& \operatorname{Prob}\left(\tilde{R}_{t+1}=\varepsilon \mid D_{t} ; \overline{\bar{\theta}}_{0}\right) u\left(\left(\bar{W}_{t}-f\right)\left(R_{f}+\alpha_{t}^{* *}\left(\varepsilon-R_{f}\right)\right)\right) \\
& \quad+\left(1-\operatorname{Prob}\left(\tilde{R}_{t+1}=\varepsilon \mid D_{t} ; \overline{\bar{\theta}}_{0}\right)\right) E_{t}\left[u\left(\left(\bar{W}_{t}-f\right)\left(R_{f}+\alpha_{t}^{* *}\left(\tilde{R}_{t+1}^{+}-R_{f}\right)\right)\right)\right]< \\
& \operatorname{Prob}\left(\tilde{R}_{t+1}=\varepsilon \mid D_{t} ; \bar{\theta}_{0}\right) u\left(\left(\bar{W}_{t}-f\right)\left(R_{f}+\alpha_{t}^{*}\left(\varepsilon-R_{f}\right)\right)\right) \\
& +\left(1-\operatorname{Prob}\left(\tilde{R}_{t+1}=\varepsilon \mid D_{t} ; \bar{\theta}_{0}\right)\right) E_{t}\left[u\left(\left(\bar{W}_{t}-f\right)\left(R_{f}+\alpha_{t}^{*}\left(\tilde{R}_{t+1}^{+}-R_{f}\right)\right)\right)\right]=u\left(\bar{W}_{t} R_{f}\right) .
\end{aligned}
$$

Therefore, by Proposition 1, the threshold value of wealth corresponding to the prior $\overline{\bar{\theta}}_{0}$ must be higher than $\bar{W}_{t}$. That is, $\bar{W}_{t}>\bar{W}_{t}$.

Conversely, adding participation costs to our learning model lowers the value of the prior that triggers nonparticipation, as shown in the proposition below.

Proposition 3: Adding a participation cost lowers the threshold value of the prior probability of fraud that triggers nonparticipation.

Proof: Suppose that $\hat{\theta}_{0}$ triggers participation in the absence of participation costs. That is,

$$
\begin{aligned}
& \operatorname{Prob}\left(\tilde{R}_{t+1}=\varepsilon \mid D_{t} ; \hat{\theta}_{0}\right) u\left(W_{t}\left(R_{f}+\alpha_{t}^{*}\left(\varepsilon-R_{f}\right)\right)\right) \\
& +\left(1-\operatorname{Prob}\left(\tilde{R}_{t+1}=\varepsilon \mid D_{t} ; \hat{\theta}_{0}\right)\right) E_{t}\left[u\left(W_{t}\left(R_{f}+\alpha_{t}^{*}\left(\tilde{R}_{t+1}^{+}-R_{f}\right)\right)\right)\right]=u\left(W_{t} R_{f}\right) .
\end{aligned}
$$


With the same prior $\hat{\theta}_{0}$, the expected utility achieved in the absence of participation costs when wealth is $\left(W_{t}-f\right)$ must be lower:

$$
\begin{aligned}
& \operatorname{Prob}\left(\tilde{R}_{t+1}=\varepsilon \mid D_{t} ; \hat{\theta}_{0}\right) u\left(\left(W_{t}-f\right)\left(R_{f}+\alpha_{t}^{* *}\left(\varepsilon-R_{f}\right)\right)\right) \\
& \quad+\left(1-\operatorname{Prob}\left(\tilde{R}_{t+1}=\varepsilon \mid D_{t} ; \hat{\theta}_{0}\right)\right) E_{t}\left[u\left(\left(W_{t}-f\right)\left(R_{f}+\alpha_{t}^{* *}\left(\tilde{R}_{t+1}^{+}-R_{f}\right)\right)\right)\right]< \\
& \operatorname{Prob}\left(\tilde{R}_{t+1}=\varepsilon \mid D_{t} ; \hat{\theta}_{0}\right) u\left(W_{t}\left(R_{f}+\alpha_{t}^{*}\left(\varepsilon-R_{f}\right)\right)\right) \\
& +\left(1-\operatorname{Prob}\left(\tilde{R}_{t+1}=\varepsilon \mid D_{t} ; \hat{\theta}_{0}\right)\right) E_{t}\left[u\left(W_{t}\left(R_{f}+\alpha_{t}^{*}\left(\tilde{R}_{t+1}^{+}-R_{f}\right)\right)\right)\right]=u\left(W_{t} R_{f}\right) .
\end{aligned}
$$

Now, the expected utility that can be achieved is decreasing in the posterior probability of fraud, $\operatorname{Prob}\left(\tilde{R}_{t+1}=\varepsilon \mid D_{t} ; \theta_{0}\right)$, and the posterior probability of fraud is, in turn, increasing in the prior probability of fraud, $\theta_{0}$, meaning that, in the case when there are participation costs, the prior probability that triggers participation must be lower than $\hat{\theta}_{0}$. 


\section{Appendix B: Derivation of marginal effects}

For the probit model in equation (31), the marginal effect of the explanatory variable on the probability of participation is given by

$$
\frac{\partial \operatorname{Prob}\left[y_{i}=1 \mid X_{i}^{p}\right]}{\partial \boldsymbol{X}_{k i}^{P}}=\alpha_{k} f\left(\boldsymbol{\alpha}^{\prime} \boldsymbol{X}_{i}^{p}\right)
$$

The marginal effect of a change in institutional quality of the country of residence is

$$
\frac{\partial \operatorname{Prob}\left[y_{i}=1 \mid \boldsymbol{X}_{i}^{p}\right]}{\partial X_{i}^{\text {res }}}=\frac{\partial \operatorname{Prob}\left[y_{i}=1 \mid \boldsymbol{X}_{i}^{p}\right]}{\partial T_{i}^{\text {inst }}} \cdot \frac{\partial T_{i}^{i n s t}}{\partial X_{i}^{\text {res }}}
$$

Here, the first factor in the above equation can be written as

$$
\frac{\partial \operatorname{Prob}\left[y_{i}=1 \mid \boldsymbol{X}_{i}^{p}\right]}{\partial T_{i}^{\text {inst }}}=f\left(\boldsymbol{\alpha}^{\prime} \boldsymbol{X}_{i}^{p}\right) a_{1}
$$

According to the definition of the $T_{i}^{\text {inst }}$ in equation (24), the second factor is given by

$$
\begin{gathered}
\frac{\partial T_{i}^{i n s t}}{\partial X_{i}^{r e s}}=\frac{\partial \sum_{j=1}^{J} \operatorname{Prob}\left[T_{i}=j \mid \boldsymbol{X}_{i}^{T}\right] \cdot j}{\partial X_{i}^{r e s}} \\
=\sum_{j=1}^{J}\left(\frac{\partial F\left(\mu_{j}-\boldsymbol{\beta}^{\prime} \boldsymbol{X}_{i}^{T}\right)}{\partial X_{i}^{r e s}}-\frac{\partial F\left(\mu_{j-1}-\boldsymbol{\beta}^{\prime} \boldsymbol{X}_{i}^{T}\right)}{\partial X_{i}^{r e s}}\right) j .
\end{gathered}
$$

For natives, the above expression is equal to

$$
\frac{\partial T_{i}^{i n s t}}{\partial X_{i}^{r e s}}=-b_{N} \sum_{j=1}^{J}\left(f\left(\mu_{j}-\boldsymbol{\beta}^{\prime} \boldsymbol{X}_{i}^{T}\right)-f\left(\mu_{j-1}-\boldsymbol{\beta}^{\prime} \boldsymbol{X}_{i}^{T}\right)\right) j
$$

whereas for immigrants, it is given by

$$
\frac{\partial T_{i}^{i n s t}}{\partial X_{i}^{r e s}}=-b_{I} \omega \sum_{j=1}^{J}\left(f\left(\mu_{j}-\boldsymbol{\beta}^{\prime} \boldsymbol{X}_{i}^{T}\right)-f\left(\mu_{j-1}-\boldsymbol{\beta}^{\prime} \boldsymbol{X}_{i}^{T}\right)\right) \cdot j
$$


Similarly, the derivative of expected trust with respect to the institutional quality of the immigrants' country of origin can be written as

$$
\frac{\partial T_{i}^{\text {inst }}}{\partial X_{i}^{\text {org }}}=-b_{I}(1-\omega) \sum_{j=1}^{J}\left(f\left(\mu_{j}-\boldsymbol{\beta}^{\prime} \boldsymbol{X}_{i}^{T}\right)-f\left(\mu_{j-1}-\boldsymbol{\beta}^{\prime} \boldsymbol{X}_{i}^{T}\right)\right) \cdot j,
$$

and the marginal effect of increased education on expected trust is given by

$$
\frac{\partial T_{i}^{i n s t}}{\partial E_{i}}=\frac{\partial T_{i}^{i n s t}}{\partial \omega_{i}} \cdot \frac{\partial \omega_{i}}{\partial E}
$$

where

$$
\frac{\partial T_{i}^{i n s t}}{\partial \omega_{i}}=-b_{I}\left(X_{i}^{r e s}-X_{i}^{\text {org }}\right) \sum_{j=1}^{J}\left(f\left(\mu_{j}-\boldsymbol{\beta}^{\prime} \boldsymbol{X}_{i}^{T}\right)-f\left(\mu_{j-1}-\boldsymbol{\beta}^{\prime} \boldsymbol{X}_{i}^{T}\right)\right) \cdot j
$$

and

$$
\frac{\partial \omega_{i}}{\partial E_{i}}=\frac{-\omega_{1}}{\left(1+\exp \left(\omega_{0}+\omega_{1} E_{i}\right)\right)^{2}}
$$

